Revisión sistemática

Pensar en Movimiento:

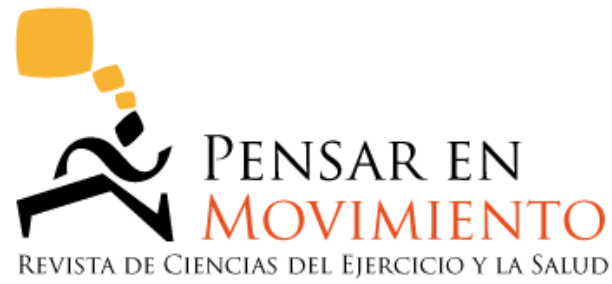

Revista de Ciencias del Ejercicio y la Salud

EISSN: $1659-4436$

Vol. 12, No. 2, pp. $1-36$

Cierre al 31 de diciembre, 2014

\title{
ACTUALIDAD EN TERMORREGULACIÓN
}

\author{
Alfredo Jesús López Dávila, Dr. \\ alfredo.lopezdavila@ucr.ac.cr \\ Universidad de Costa Rica \\ Costa Rica \\ Fecha de recepción: 23-07-2014- Fechas de reenvíos: 01-10-14/12-11-2014/03-12-2014 \\ Fecha de aceptación: 03-12-2014 Fecha de publicación: 12/12/14 \\ doi: http://dx.doi.org/10.15517/pensarmov.v12i2.14918
}

\section{Resumen}

López-Dávila, A. L. (2014). Actualidad en termorregulación. PensAR en Movimiento: Revista de Ciencias del Ejercicio y la Salud, 12 (2), 1-36. Esta revisión tiene como objetivo presentar avances recientes en la comprensión de los mecanismos fisiológicos de la termorregulación en mamíferos, que pueden dividirse en dos tipos que incluyen la termorregulación refleja (o autonómica) y la termorregulación de conducta. En la termorregulación refleja, que es totalmente ajena a la voluntad del individuo, existen termorreceptores que detectan los estímulos térmicos. La información detectada por los receptores es enviada por vías aferentes hasta el hipotálamo, con relevos en la médula espinal y el mesencéfalo. El centro integrador hipotalámico organiza su respuesta a los estímulos térmicos y envía señales nerviosas a través de vías eferentes con relevos en la médula oblongada y la médula espinal. Estas señales alcanzan finalmente a los órganos efectores capaces de conservar o disipar la energía térmica, de manera que la temperatura corporal permanece constante. En la actualidad, cada vez existe más evidencia que sugiere un alto grado de integración fisiológica entre la termorregulación refleja, el balance energético y la actividad metabólica, lo que hace pensar en la manipulación de la termorregulación refleja como una estrategia para tratar problemas metabólicos o influenciar la composición corporal. En la termorregulación de conducta, que depende de decisiones voluntarias, los estímulos térmicos son detectados por los

$$
-1 \text { - }
$$

\section{c) (i) (2)}

Esta obra está bajo una 
mismos receptores. Las vías aferentes transportan la información térmica a la médula espinal, el tálamo y la corteza cerebral, lo que influencia el grado de confort térmico percibido y las decisiones del individuo para ganar o perder calor. Los recientes descubrimientos también han traído consigo nuevas interrogantes que se exponen en la parte final de esta revisión.

Palabras clave: termorregulación; metabolismo; obesidad, temperatura corporal; fisiología del ejercicio

\begin{abstract}
The aim of this review is to present recent advances in the understanding of the physiological mechanisms of thermoregulation in mammals, which can be divided into two types including reflex (or autonomic) and behavioral thermoregulation. In reflex thermoregulation, which is totally beyond the voluntary control of the individual, thermoreceptors detect thermal stimuli. Afferent pathways transport information sensed by receptors to the hypothalamus, with relays in the spinal cord and the midbrain. The hypothalamic integration center coordinates its response to the thermal stimuli and sends neural signals through efferent pathways with relays in the medulla and the spinal cord. These signals finally reach effectors that are capable of conserving or dissipating thermal energy in order for body temperature to remain constant. Today, a growing body of evidence suggests considerable physiologic integration between reflex thermoregulation, energy balance and metabolism, which makes considering manipulation of reflex thermoregulation a potential strategy in order to treat metabolic conditions or influence body composition. In behavioral thermoregulation, which relies on voluntary decisions, thermal stimuli are detected by the same receptors. Afferent pathways transport thermal information to the spinal cord, thalamus and cerebral cortex, which influences the perception of thermal comfort and the decisions of the individual in order to gain or lose heat. The recent findings have also brought new questions that are discussed at the end of this review.
\end{abstract}

Keywords: thermoregulation; metabolism; obesity; body temperature; exercise physiology

\title{
Introducción
}

En mamíferos el control de la temperatura corporal es vital. El estado de consciencia y el control motor normal ocurren en un rango de temperatura corporal de 36 a 39 grados centígrados y las desviaciones significativas de estos valores alteran las propiedades moleculares de las células, lo que causa desde la incapacidad para ejecutar actividades motoras hasta la pérdida de la consciencia (Clapham, 2012; Morrison \& Nakamura, 2011; Morrison, Nakamura, \& Madden, 2008).

La "termogénesis obligatoria" (aquella resultante de las funciones metabólicas básicas) puede mantener estable la temperatura corporal sin la participación de mecanismos adicionales. A la temperatura ambiental más baja en que ocurre lo anterior - 2 -

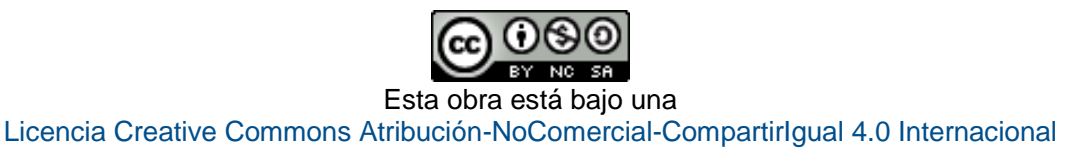


se le denomina temperatura de termoneutralidad. En especies pequeñas, como roedores, debido a su gran relación área de superficie corporal / volumen corporal, que facilita la pérdida de calor, la temperatura de termoneutralidad es relativamente alta (unos $30{ }^{\circ} \mathrm{C}$ ). En el caso de especies más grandes como el ser humano, esta temperatura es de unos $23{ }^{\circ} \mathrm{C}$ (López, Alvarez, Nogueiras, \& Diéguez, 2013). La presente revisión tiene como objetivo explicar los diferentes mecanismos fisiológicos que permiten el mantenimiento de la temperatura corporal en su rango compatible con la vida, cuando la temperatura ambiental es diferente a la de termoneutralidad o cuando las funciones metabólicas van más allá de las básicas, como en el caso del ejercicio. Estos mecanismos se pueden dividir en aquellos de tipo reflejo (o autonómico) y de conducta (o voluntario). En los mecanismos reflejos, el sistema nervioso autónomo activa una serie de respuestas termorreguladoras ante variaciones de la temperatura corporal, de forma automática y sin mediación de la voluntad del sujeto. En los mecanismos de conducta, el individuo toma conscientemente ciertas decisiones cuando siente que pierde su confort térmico, aunque su temperatura corporal no necesariamente haya cambiado. Ambos tipos de regulación contribuyen a conservar la homeostasis térmica.

En el caso de la termorregulación refleja, debido a la sofisticación experimental de los estudios más recientes, buena parte de la evidencia por presentar ha sido obtenida a partir de modelos animales, particularmente roedores, sobre todo en los estudios de los circuitos neurales en el sistema nervioso central. No obstante, es de esperar que el esquema resultante esté altamente conservado en humanos, como ocurre en otras áreas de la fisiología. En la regulación de conducta se incluirá información experimental obtenida tanto de modelos animales como de seres humanos.

\section{Termorregulación refleja}

En 1784, en Praga, el anatomista Georg Prochaska utilizó por primera vez el concepto de arco reflejo, que hoy se define como una respuesta estereotipada, automática, inmediata e involuntaria ante un estímulo sensorial específico, e incluye las siguientes partes: variable regulada, estímulo, receptor, vía aferente, centro integrador, vía eferente, efector y respuesta (Clarac, 2008). El arco reflejo tiene tres grandes modalidades que permiten regular diferentes variables fisiológicas: a) retrocontrol negativo, b) retrocontrol positivo y c) retrocontrol anticipado. Este concepto tradicional constituye una forma básica de organizar la información fisiológica hasta hoy, especialmente para explicar mecanismos autonómicos, como es el caso de la termorregulación refleja. Por lo anterior, en esta sección, se usará este esquema que data de los inicios de la revolución industrial, para presentar evidencia científica recolectada en la era actual, mediante el uso de los recursos de la biología molecular.

Como se expondrá a lo largo de esta sección, la termorregulación refleja en última

instancia producirá dos grandes fenómenos que son la respuesta termorreguladora al frío 
(o RTF, ver tabla 2) y respuesta termorreguladora al calor (o RTC, tabla 3$)^{11}$. La RTF es una combinación integrada de respuestas automáticas que incluye termogénesis simpática en el tejido adiposo pardo, termogénesis por tremor en el músculo esquelético, incremento en la producción de dióxido de carbono espirado por aumento de la actividad metabólica y taquicardia. Por su parte, la RTC incluye vasodilatación cutánea, taquicardia y sudoración.

En la figura 1 se representa un esquema general de la termorregulación refleja y en la figura 2 el mismo mecanismo, pero de una forma detallada. El significado de las abreviaturas utilizadas en la figura 2 se explica en la tabla 1.

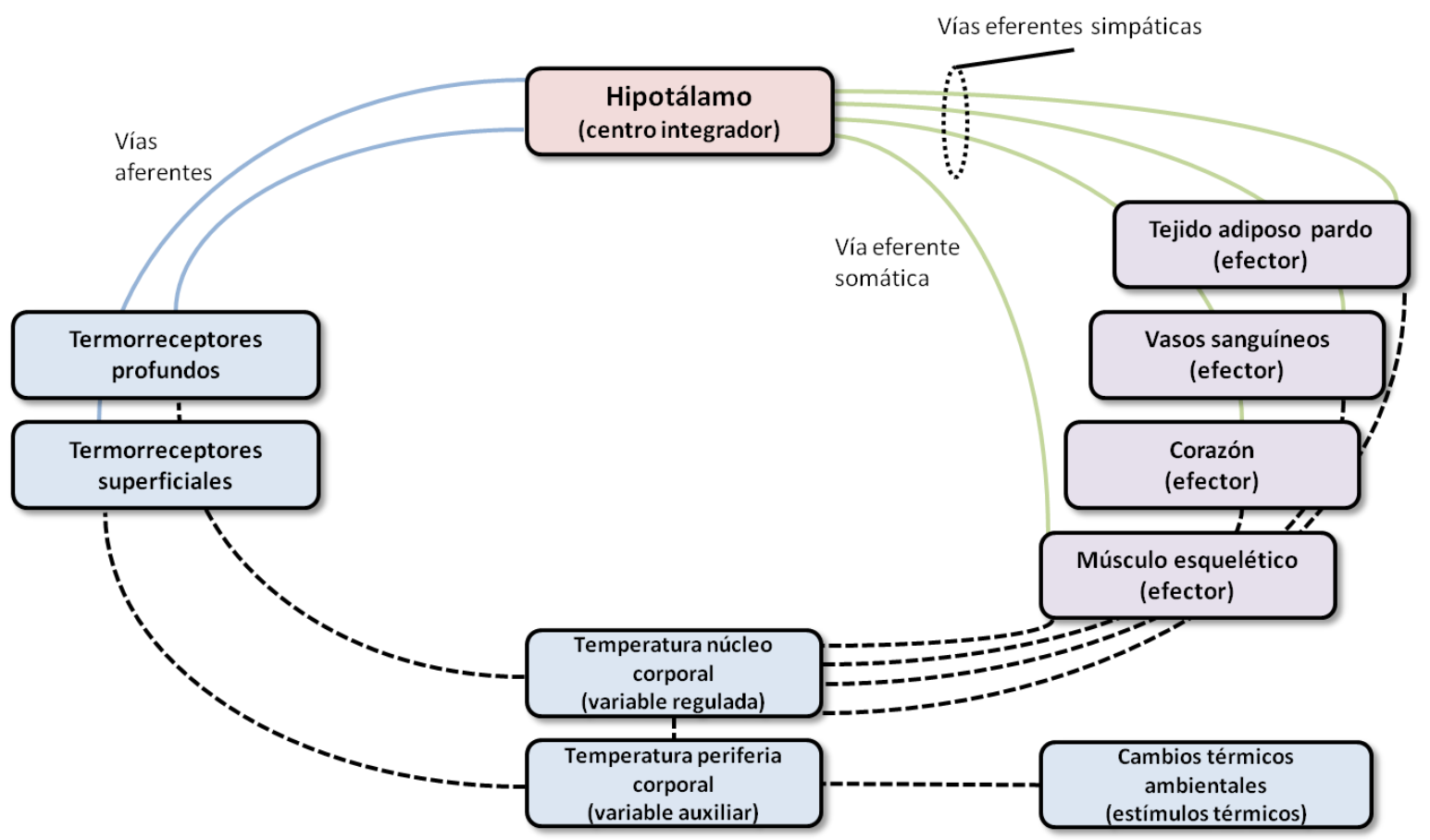

Figura 1. Esquema general de la termorregulación refleja. Los termorreceptores superficiales y profundos detectan cambios en la temperatura del núcleo y la periferia corporal. Esta información es enviada por vías aferentes nerviosas al centro integrador (hipotálamo). En función de la información térmica recibida, el hipotálamo activa a través de vías eferentes somáticas y autonómicas (simpáticas) una serie de órganos efectores capaces de generar o disipar calor, de manera que la temperatura del núcleo corporal vuelve a su punto de ajuste. La variable regulada es la temperatura del núcleo corporal, mientras que la temperatura de la periferia es una variable auxiliar que responde a cambios en la temperatura ambiental y que permite activar la termorregulación refleja incluso antes de que estos últimos alteren la temperatura del núcleo corporal. Las líneas continuas denotan conexiones nerviosas. Las líneas discontinuas denotan transmisión de la energía térmica por convección y conducción. Fuente: elaboración propia.

${ }^{1}$ Con excepción de RTF y RTC, todas las abreviaturas utilizadas en esta revisión hacen referencia al idioma inglés. 


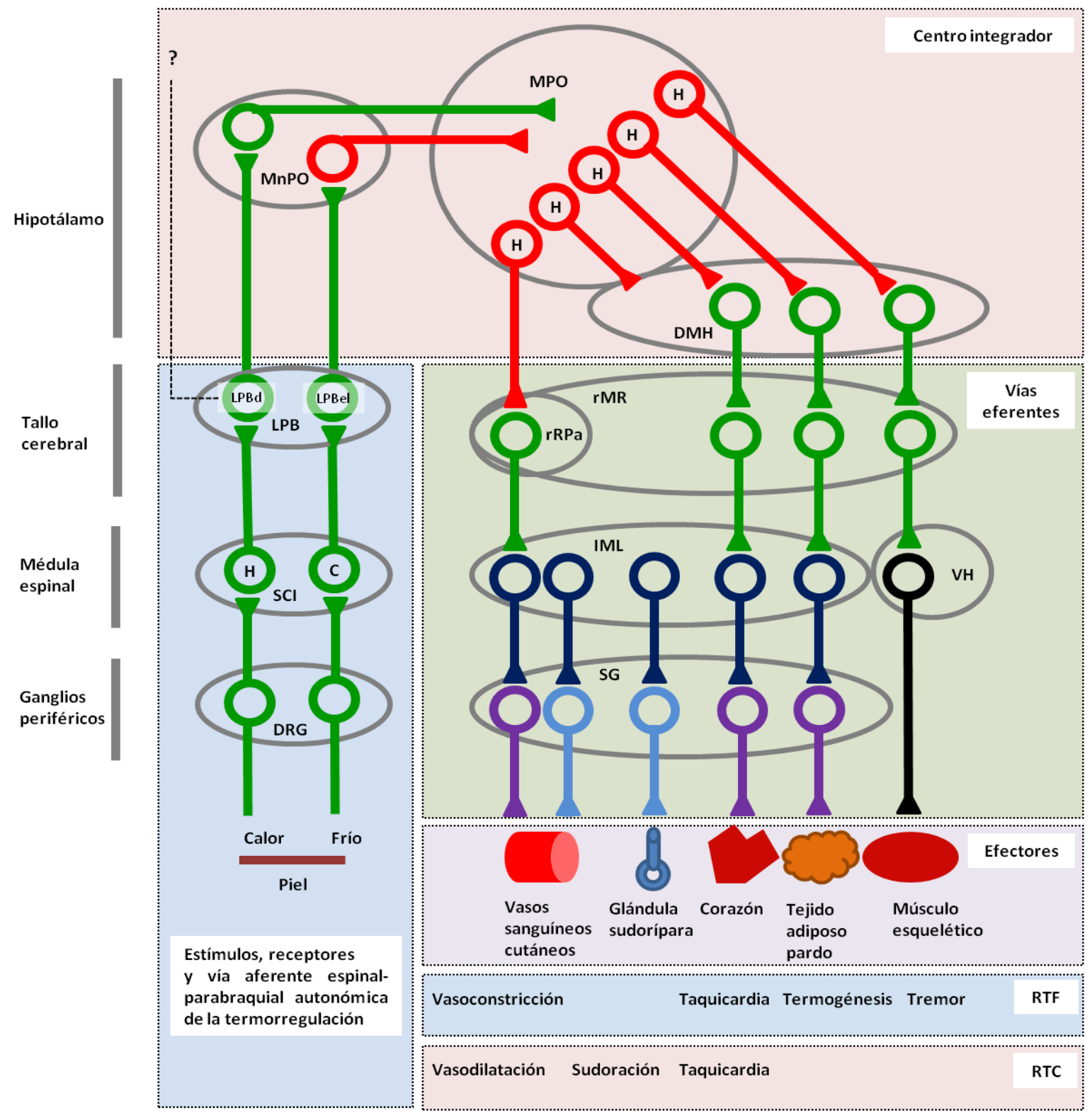

Figura 2. Esquema completo de la termorregulación refleja. Las líneas grises de la izquierda indican las estructuras macroscópicas del sistema nervioso donde se ubican los ganglios y núcleos (representados por esferas grises) que contienen las neuronas involucradas. De color verde se representan las neuronas secretoras de glutamato, de rojo las neuronas secretoras de GABA, en azul oscuro las neuronas preganglionares simpáticas secretoras de acetilcolina, morado, neuronas postganglionares simpáticas secretoras de norepinefrina y sus cotransmisores, celeste, neuronas postganglionares secretoras de acetilcolina (en los vasos sanguíneos están presentes solo en la piel glabra) y negro, motoneuronas inferiores alfa y gama secretoras de acetilcolina. Línea discontinua con símbolo de pregunta: no se sabe exactamente de qué manera las proyecciones del LPBd son integradas en el sistema nervioso central de manera que induzcan taquicardia como parte de la RTC. Aunque se sabe que los vasos sanguíneos cutáneos y las glándulas sudoríparas poseen inervación colinérgica, no está del todo claro si esta es a su vez controlada por el eje DMH-rMR o por otras proyecciones desde la MPO. Los núcleos MnPO y MPO se ubican en la región preóptica del hipotálamo mientras que el núcleo DMH se ubica en la región tuberal del mismo órgano. Nótese que el código de colores de la figura 1 para las diferentes partes del arco reflejo está conservado. Ver significado de las abreviaturas en la tabla 1. La vía aferente de la cara no se representa por falta de espacio. Fuente: elaboración propia a partir de información disponible en Morrison, Madden, \& Tupone, 2014; Morrison \& Nakamura, 2011; Morrison et al., 2008; Nakamura, 2011; Romanovsky et al., 2009; Tupone, Madden, \& Morrison, 2014.

$$
-5 \text { - }
$$

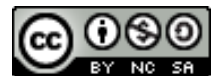

Esta obra está bajo una

Licencia Creative Commons Atribución-NoComercial-Compartirlgual 4.0 Internacional 
Tabla 1.

Abreviaturas utilizadas en la representación de la termorregulación refleja de la figura 2.

\begin{tabular}{ll}
\hline Abreviatura & Significado \\
\hline DRG & Ganglio de la raíz dorsal \\
SCI & Lámina 1 del asta dorsal de la médula espinal \\
LPB & Núcleo parabraquial lateral del mesencéfalo \\
LPBd & Subnúcleo dorsal del LPB \\
LPBel & Subnúcleo externo lateral del LPB \\
MnPO & Núcleo preóptico mediano de la región preóptica del hipotálamo \\
MPO & Área preóptica medial de la región preóptica del hipotálamo \\
DMH & Núcleo dorsomedial del hipotálamo \\
rMR & Por su ubicación anatómica, se trata de una región de la médula oblongada \\
& ventromedial rostral al polo rostral del complejo olivario inferior. A esta \\
& estructura pertenece el rRPA. En ciertas referencias la rMR es mencionada \\
& simplemente como región raphe de la médula oblongada rostral o \\
& alternativamente, médula oblongada ventromedial rostral. Estas divergencias \\
& se deben a lo novedoso del estudio de esta zona del tallo cerebral en su rol \\
rRPA & específico de la termorregulación refleja \\
IML & Núcleo pálido raphe rostral de la médula oblongada \\
SG & Columna intermedio lateral de la médula espinal \\
VH & Cadena paravertebral de ganglios simpáticos \\
H y C en SCl & Asta ventral de la médula espinal \\
& Neuronas termorreceptivas específicas "calientes" y "frías" de la lámina I del \\
H en MPO & asta dorsal de la médula espinal, respectivamente \\
RTF* & Neuronas calientes de la MPO \\
RTC* & Respuesta termorreguladora al frío \\
\hline
\end{tabular}

* Con excepción de estas dos abreviaturas, todas hacen referencias al idioma inglés.

Fuente: elaboración propia

\section{Variables reguladas}

Desde este punto de vista térmico, el cuerpo se divide en dos compartimentos principales: el núcleo (incluye al sistema nervioso central y las vísceras toracoabdominales) que térmicamente es más homogéneo y la periferia (el resto del cuerpo, incluso la piel) que es térmicamente más heterogénea (Romanovsky et al., 2009). Entre ambos compartimentos térmicos existe un gradiente de temperatura, cuya magnitud depende de la tasa de transferencia de calor entre los tejidos por convección y conducción (González-Alonso, 2012). Lo anterior da origen a dos variables importantes en la termorregulación de tipo reflejo, las cuales son: a) la temperatura del núcleo corporal que es considerada la variable principal y es sujeto de regulación fisiológica y b) la temperatura periférica, considerada una variable auxiliar que si bien no es el sujeto principal de regulación fisiológica, contribuye a la regulación de la variable principal (Romanovsky et al., 2009).

$$
-6-
$$


La variable principal es regulada por un mecanismo de retrocontrol negativo, en el cual los cambios en la magnitud de la variable en cuestión son detectados por los receptores y contrarrestados de forma refleja por acciones organizadas por el centro integrador (por ejemplo, si los receptores detectan un incremento de la magnitud de la temperatura del núcleo corporal, el hipotálamo iniciará una respuesta que la disminuye y viceversa). De esta forma la variable principal se mantiene prácticamente constante en 37 ${ }^{\circ} \mathrm{C}$ en los seres humanos. Al valor relativamente constante en el cual una variable regulada se establece, producto del retrocontrol negativo, se le denomina punto de ajuste. Al igual que la temperatura del núcleo corporal, otras variables fisiológicas del organismo reguladas también por retrocontrol negativo, tienen su punto de ajuste y algunos ejemplos de ello son los siguientes: a) la frecuencia cardiaca se mantiene alrededor de 70 latidos por minuto, b) la presión arterial media tiene una magnitud de unos 93 milímetros de mercurio, c) el gasto cardiaco ronda los 5 litros de sangre por minuto y d) la ventilación pulmonar se mantiene en unos 12 litros de aire por minuto.

La temperatura del núcleo corporal se regula adicionalmente por retrocontrol anticipado (Clapham, 2012). Esto último se ilustra experimentalmente cuando en animales anestesiados esta variable no solo no se reduce, sino que incluso tiende a aumentar levemente cuando estos son expuestos a ambientes fríos que reducen la temperatura de la periferia corporal (Morrison \& Nakamura, 2011; Morrison et al., 2008; Romanovsky et al., 2009).

\section{Estímulos}

Los estímulos del mecanismo de la termorregulación refleja consisten en los aumentos y disminuciones de la magnitud de las variables principal y auxiliar. La temperatura del núcleo o de la periferia corporal puede aumentar debido a factores tales como las condiciones ambientales, la práctica de ejercicio, la ingesta de bebidas y alimentos calientes y el uso de ciertas prendas de vestir e implementos deportivos, entre otros. Por su parte, los descensos en la temperatura corporal pueden ser inducidos por condiciones ambientales, hemorragias, ingesta de bebidas o alimentos fríos, o la falta de una vestimenta adecuada. Estos estímulos serán detectados por los termorreceptores, lo que a su vez activará la RTC o RTF según corresponda, a través de los mencionados mecanismos reflejos de retrocontrol negativo y anticipado. Nótese que los estímulos pueden aparecer por circunstancias ajenas al sujeto, como las condiciones ambientales, o por fenómenos que ocurren en el cuerpo mismo del individuo, como la realización de ejercicio o una hemorragia.

\section{Receptores}

$-7-$

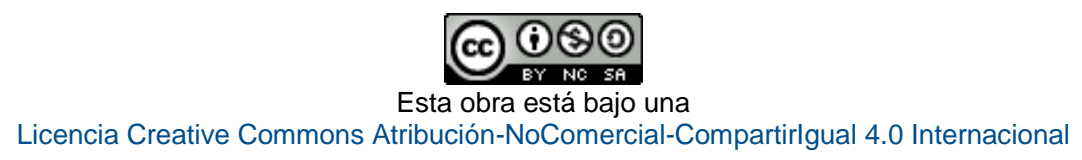


En un piano, un golpe sobre una tecla es transformada en un sonido. En una computadora, un golpe en una tecla es transformado en una letra en la pantalla. En un termómetro, la energía calórica es transformada en desplazamiento lineal del mercurio y en una turbina de una represa hidroeléctrica, el desplazamiento del agua es transformado en electricidad. En el fondo, todos estos instrumentos funcionan igual: captan una forma específica de energía y emiten una forma distinta. A este proceso se le llama transducción y a estos aparatos, transductores.

Los órganos sensoriales funcionan exactamente igual que los instrumentos transductores de energía anteriormente descritos y les permiten a los animales percibir su entorno. Estos órganos tienen células especializadas llamadas receptores que captan diferentes formas de energía y las transducen en todos los casos en energía eléctrica. A la energía que es captada por el receptor del órgano sensorial se le llama estímulo. La energía lumínica que llega a los ojos en forma de luz visible, la energía mecánica que llega al oído en forma de ondas de presión de aire o que llega hasta la piel transmitida por los objetos que tocamos, la energía química en forma de moléculas odorantes que entran por nuestra nariz o en forma de moléculas presentes en los alimentos que ingerimos, son diferentes estímulos que son captados por diferentes receptores y transducidos en energía eléctrica que viaja por nuestro sistema nervioso en forma de potenciales de acción. En el sistema nervioso no hay luz, ni sombra, imagen, sonido, tacto, olor, sabor o dolor; solo existen estas señales eléctricas que son generadas por los receptores a partir de los estímulos. Esas señales eléctricas activan a nuestras sinapsis y esto es lo que finalmente causa en nuestro cerebro las experiencias sensoriales que tenemos cada día.

En el pasado se ha comprobado la existencia de receptores de temperatura (termorreceptores) en la periferia (ubicados principalmente en la piel) y en el núcleo corporal (ubicados en el abdomen, cerebro, músculos, grandes vasos sanguíneos, en las regiones cervicales y torácicas de la médula espinal y especialmente en la región preóptica y región anterior hipotalámicas). La existencia de termorreceptores en los dos compartimentos térmicos principales se entiende como una ventaja evolutiva, pues permite detectar rápidamente cualquier cambio de temperatura en cada uno de ellos, sin depender de la conducción y convección térmicas entre ambos (González-Alonso, 2012).

Los termorreceptores mejor estudiados son los de la piel y consisten principalmente en neuronas que se clasifican en tipo $A \beta, A \delta$ (ambas mielinizadas) y $C$ (no mielinizadas). Recientemente, se ha sugerido que los queratinocitos de la piel también tienen función termorreceptora. Estos termorreceptores permiten en el caso de los mamíferos, discriminar temperaturas en el rango de los $-10{ }^{\circ} \mathrm{C}$ (percibido como extremadamente frío) a $60{ }^{\circ} \mathrm{C}$ (percibido como extremadamente caliente) aproximadamente. En este rango, las temperaturas se pueden diferenciar entre cuatro modalidades sensoriales: a) frío nocivo entre $-10^{\circ} \mathrm{C}$ y $15^{\circ} \mathrm{C}$, puesto que produce dolor, b) frío inocuo entre $15^{\circ} \mathrm{C}$ y $30{ }^{\circ} \mathrm{C}$, c) calor inocuo entre $30{ }^{\circ} \mathrm{C}$ y $42{ }^{\circ} \mathrm{C}$ y d) calor nocivo entre $43{ }^{\circ} \mathrm{C}$ y $60^{\circ} \mathrm{C}$, ya que genera dolor (Dhaka, Viswanath, \& Patapoutian, 2006;

- 8 -

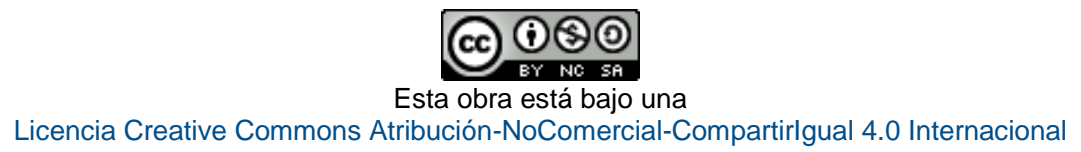


Lumpkin \& Caterina, 2007; Purves et al., 2012; Schepers \& Ringkamp, 2010). Se ha demostrado que los termorreceptores cutáneos son polimodales porque no solo responden a estímulos térmicos, sino que responden en diferente medida a otros tipos de estímulos, tales como mecánicos y químicos (Belmonte \& Viana, 2008; Lumpkin \& Caterina, 2007; Schepers \& Ringkamp, 2010).

Los estímulos aplicados sobre la piel producen una despolarización de los termorreceptores y esto constituye precisamente la transducción del estímulo (conversión a energía eléctrica). A su vez, la despolarización es capaz de inducir, si se alcanza el umbral eléctrico, potenciales de acción en los termorreceptores. A este segundo proceso se le llama transformación y su importancia radica en que los potenciales de acción en un receptor permitan activar por medio de la secreción de neurotransmisores a las neuronas que hacen sinapsis con este. Por medio de la transducción y transformación, el estímulo térmico puede ser detectado en el termorreceptor y transmitido al resto del sistema nervioso (Fahlke, Linke, Rassler, \& Wiesner, 2008).

Algunos aspectos clave para la comprensión molecular del funcionamiento de la transducción y transformación de los termorreceptores se originan de la reciente identificación de la superfamilia de canales catiónicos de potencial de receptor transitorio (TRP) expresados en los termorreceptores. Hasta el momento se conocen aproximadamente 30 diferentes TRP agrupados en siete subfamilias. Los TRP son fuertes candidatos a ser los canales iónicos capaces de conferirle a las neuronas la facultad de detectar la temperatura, entre otros estímulos. Al igual que los termorreceptores que los expresan, los TRP son polimodales y se activan de manera transitoria a diferentes umbrales y rangos de energía térmica. Lo anterior permite la transducción del estímulo térmico correspondiente a las cuatro modalidades sensoriales anteriormente mencionadas (Belmonte \& Viana, 2008; Bharate \& Bharate, 2012; Dhaka et al., 2006; Journigan \& Zaveri, 2013; Lumpkin \& Caterina, 2007; Schepers \& Ringkamp, 2010).

\section{Vías aferentes. Vía espinal-parabraquial autonómica de la termorregulación refleja}

En esta vía los termorreceptores constituyen neuronas aferentes primarias cuyos somas se ubican en los ganglios de la raíz dorsal y núcleo espinal del nervio trigémino y transmiten información térmica periférica somática del cuerpo y la cara respectivamente. En el caso del cuerpo, el axón de estas neuronas hace sinapsis con neuronas aferentes secundarias en la lámina I del asta dorsal de la médula espinal. En el caso de la cara, la sinapsis con las neuronas aferentes secundarias ocurre en la zona dorsal de la porción caudal y media de la médula oblongada, específicamente en el núcleo espinal del trigémino. El neurotransmisor secretado en estas sinapsis es glutamato, cuyo efecto es excitatorio (Morrison et al., 2014; Purves et al., 2012; Romanovsky et al., 2009).

Las neuronas aferentes secundarias de la lámina I del asta dorsal se dividen en poblaciones separadas que incluyen: a) neuronas nociceptivas específicas activadas por estímulos nociceptivos mecánicos y térmicos, b) neuronas nociceptivas polimodales

- 9 -

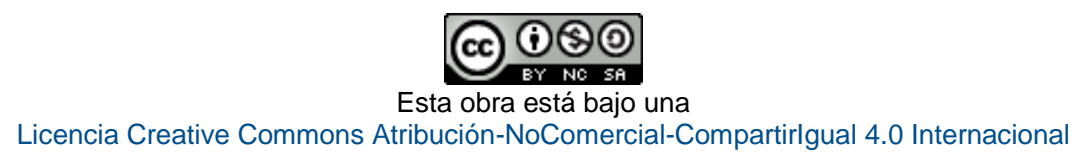


activadas ante estímulos nociceptivos mecánicos y estímulos térmicos de frío y calor y c) neuronas termorreceptivas específicas que se clasifican a su vez en "frías" y "calientes", activadas cuando la piel es expuesta a frío inocuo y calor inocuo respectivamente. Se cree que esta tercera población es la involucrada en la transmisión de señales aferentes relacionadas con la termorregulación refleja (Morrison \& Nakamura, 2011).

En la vía aferente del cuerpo, las neuronas frías de la lámina I del asta dorsal se proyectan hacia el núcleo parabraquial lateral del mesencéfalo (LPB), específicamente a los subnúcleos externo lateral y central (LPBel y LPBc respectivamente). Por su parte las neuronas calientes se proyectan al subnúcleo dorsal del LPB (LPBd). Dado que las neuronas frías y calientes de la lámina I secretan glutamato, su activación estimula a las neuronas del LPB. Las neuronas del LPBel, LPBc y LPBd son neuronas aferentes terciarias que se proyectan a su vez hacia la región preóptica del hipotálamo (POA), principalmente a la línea media de esta estructura, donde se ubica el núcleo preóptico mediano (MnPO) y ahí activan a ciertas neuronas con glutamato (Morrison et al., 2014; Romanovsky et al., 2009; Tupone et al., 2014). En la vía aferente de la cara, las neuronas aferentes secundarias del núcleo espinal del trigémino también tienen proyección a las neuronas aferentes terciarias del LPB del mesencéfalo, de donde la información térmica es igualmente transmitida al MnPO (Morrison \& Nakamura, 2011).

La POA es la estructura que contiene algunos de los centros integradores más relevantes de la termorregulación refleja y se ubica en la unión del telencéfalo y diencéfalo, en la zona rostral del hipotálamo (Clapham, 2012), justo detrás del quiasma óptico. Nótese que la vía aferente, en este caso llamada espinal-parabraquial autonómica, inicia en los receptores periféricos del cuerpo y la cara y termina en el MnPO del hipotálamo.

\section{Centro integrador hipotalámico}

\section{Mecanismos integradores en el área preóptica medial.}

En el área preóptica medial (MPO) de la POA hay neuronas cuya actividad depende altamente de la temperatura local del hipotálamo. Estas neuronas "calientes" del MPO son inhibitorias (secretan GABA), están tónicamente activas a temperatura fisiológica y su actividad se reduce si el hipotálamo se enfría (Romanovsky et al., 2009; Tupone et al., 2014).

La actividad de estas neuronas calientes del MPO no solo es afectada por la temperatura hipotalámica, sino también por cambios de temperatura de otras regiones del núcleo corporal, como la médula espinal, sangre (el MPO está altamente perfundido) y vísceras (esófago, estómago, grandes venas intraabdominales, mesenterio, entre otras). Aunque -con la excepción lógica de la sangre- no se conoce exactamente la forma en que la información térmica del núcleo corporal es enviada hasta el MPO, se especula -entre otras posibilidades- que los termorreceptores cutáneos tienen canales TRP cerca de su punto de sinapsis en el asta dorsal, por lo que serían capaces de enviar aferencias por la

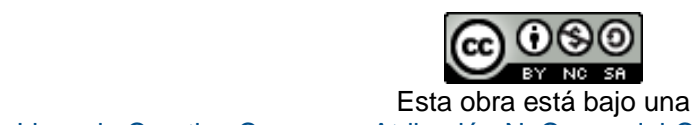


vía espinal-parabraquial autonómica referentes a la temperatura de la médula espinal, además de la información térmica cutánea (Morrison et al., 2014; Morrison et al., 2008; Nakamura, 2011).

En el abdomen, el nervio vago posee fibras aferentes termorreceptoras. No obstante, no existen experimentos concluyentes que indiquen claramente cómo esa información es transmitida finalmente hasta la POA, aunque podría ser por una vía nerviosa no completamente caracterizada, que involucra al nervio vago, pasa por el ganglio vagal nodoso y llega al núcleo del tracto solitario (Morrison et al., 2008; Romanovsky et al., 2009), de donde la información finalmente se proyectaría por conexiones neuronales hacia el hipotálamo, tal y como ocurre con muchas otras aferencias viscerales (Harrold, Dovey, Blundell, \& Halford, 2012). Esta información vagal aferente incluye, además, señales metabólicas relacionadas con la disponibilidad de sustratos energéticos y la capacidad potencial para oxidarlos dada por la presión parcial de oxígeno arterial, presión sanguínea arterial y frecuencia cardiaca, entre otros. Esto claramente sugiere integración entre señales aferentes térmicas y metabólicas que apenas se comienza a investigar experimentalmente (Morrison et al., 2014; Tupone et al., 2014).

Lo que sí es claro es que las neuronas calientes del MPO detectan la temperatura del núcleo corporal y se cree que esto es importante para la respuesta termorreguladora cuando los cambios de temperatura se originan dentro del cuerpo (ejercicio, ingesta de líquidos fríos o calientes, hemorragia, etc.) o cuando las condiciones ambientales son tan extremas, que los mecanismos termorreguladores dependientes de la temperatura de la piel no son suficientes, pues no logran mantener la temperatura del núcleo corporal en su punto de ajuste de $37^{\circ} \mathrm{C}$ (Nakamura, 2011), como ocurre durante la actividad física.

Las neuronas calientes de la MPO son sensibles a la temperatura de la periferia corporal, pues el descenso de la temperatura de la piel reduce su actividad y su sensibilidad ante los cambios de temperatura del hipotálamo. Esto implica que estas neuronas integran la información térmica del núcleo y la periferia corporal. Además, las neuronas calientes de la MPO son capaces de controlar a los órganos efectores de la termorregulación refleja, pues cuando experimentalmente se activan por aumentos de la temperatura corporal se producen las respuestas típicas de RTC, mientras que cuando estas neuronas se inactivan por disminución de la temperatura corporal producen las respuestas típicas de la RTF (Morrison et al., 2014; Morrison \& Nakamura, 2011; Morrison et al., 2008; Nakamura, 2011).

En resumen, las neuronas calientes de la MPO son un punto donde confluye y se integra la información de la temperatura del núcleo y la periferia corporal, además de que controlan a los órganos efectores capaces de disipar o conservar calor en función de los cambios térmicos detectados. Por lo anterior, se les considera, actualmente, parte esencial del centro integrador de la termorregulación refleja.

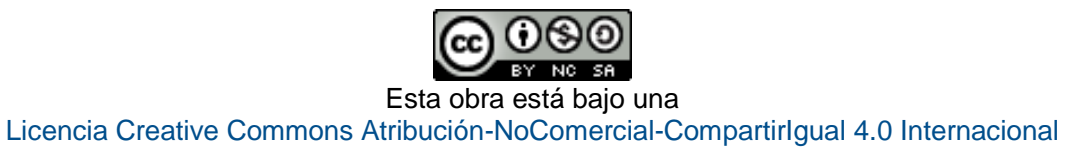




\section{Integración de la respuesta termorreguladora al frío}

En condiciones termoneutrales, las neuronas calientes de la MPO secretan permanentemente GABA sobre el hipotálamo dorsomedial (DMH), estructura ubicada de forma caudal a la POA y ventral al tálamo (Clapham, 2012), así como sobre el núcleo pálido raphe rostral de la médula oblongada ( $\mathrm{rRPa}$ ), lo que causa inhibición de estas dos estructuras (Morrison et al., 2014; Morrison \& Nakamura, 2011; Morrison et al., 2008; Nakamura, 2011; Romanovsky et al., 2009).

Cuando la temperatura de la piel disminuye, la activación de las neuronas LPBel y LPBC estimula a ciertas neuronas secretoras de GABA ubicadas en la MnPO que producen inhibición de las neuronas calientes del MPO, cuyo efecto inhibitorio sobre las neuronas del $\mathrm{DMH}$ y del rRPa quedará bloqueado, mientras la temperatura de la piel siga baja. La desinhibición resultante del DMH a su vez produce un estímulo excitatorio sobre neuronas del rMR, que a su vez activará la RTF. El rMR es una región de la médula oblongada ventromedial rostral al polo rostral del complejo olivario inferior e incluye al rRPa, el núcleo magno raphe (RMg) adyacente y el núcleo piramidal lateral (Nakamura, 2011; Romanovsky et al., 2009). La conexión entre las estructuras hipotalámicas y de la médula oblongada está posiblemente dada por el tecmentum del puente (Shibasaki \& Crandall, 2010).

\section{Integración de la respuesta termorreguladora al calor}

Aunque este apartado se ha estudiado menos, se ha propuesto que los termorreceptores de calor inocuo activan a las neuronas calientes del asta dorsal y estas, por medio de glutamato, activan a las neuronas del LPBd, que a su vez estimulan con glutamato a ciertas neuronas del MnPO secretoras de glutamato (y no de GABA). Estas neuronas activarían a las neuronas calientes del MPO, lo que causa la inhibición del DMH y el rMR, inactiva la RTF y activa la TRC (Morrison et al., 2014; Morrison \& Nakamura, 2011; Nakamura, 2011; Romanovsky et al., 2009; Tupone et al., 2014).

\section{Vías eferentes}

\section{Las neuronas del DMH controlan a las del rMR}

El rMR contiene neuronas premotoras simpáticas capaces de reclutar a los efectores que activan la RTF. La actividad de estas neuronas depende en gran medida de la activación de las neuronas del DMH (Morrison \& Nakamura, 2011; Morrison et al., 2008; Nakamura, 2011). Las vías eferentes del arco reflejo termorregulador reclutan en última instancia neuronas del sistema nervioso simpático. Diferentes grupos de neuronas del centro integrador y de las demás estructuras del sistema nervioso central involucradas controlan a diferentes grupos de neuronas simpáticas, que a su vez inervan órganos efectores específicos (inervación paralela). Lo anterior permite que los diferentes -12 -

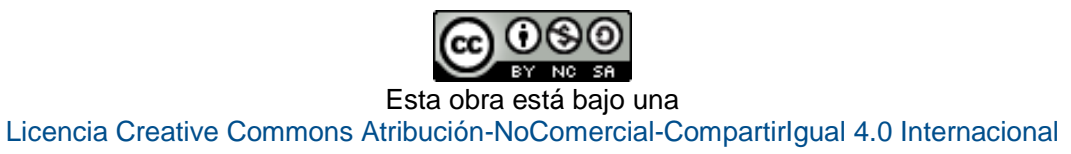


efectores reciban un diferente grado de estímulo simpático y por lo tanto, cierto grado de activación para una temperatura corporal dada (Clapham, 2012).

En el caso específico de la vía eferente que induce vasoconstricción cutánea, parte de la RTF, se ha señalado que esta depende de neuronas del rMR (posiblemente ubicadas en el $\mathrm{rRPa}$ ) cuya actividad es dependiente de neuronas inhibitorias del MPO y no de las neuronas excitatorias del $\mathrm{DMH}$, como ocurre con otros componentes de la RTF. Esta excepción se sustenta anatómicamente, pues se han detectado neuronas secretoras de GABA en el MPO que se proyectan directamente al rRPA del rMR, mientras que otras se proyectan al $\mathrm{DMH}$. Este fenómeno ilustra con más claridad la existencia de órganos efectores termorreguladores activados por vías eferentes paralelas. También se debe aclarar, que en el rRPa hay adicionalmente neuronas que sí son activadas por el $\mathrm{DMH}$, pero estas no causan activación de la vasoconstricción cutánea, sino que median la activación de los otros órganos efectores de la RTF, tal y como lo hacen las neuronas del resto del rMR. Por motivos de espacio, esta última idea no está representada en la figura $\underline{2}$ (Morrison \& Nakamura, 2011; Morrison et al., 2008; Nakamura, 2011; Romanovsky et al., 2009).

No solamente en la MPO hay grupos de neuronas que controlan efectores diferentes. Se ha demostrado que dentro del $\mathrm{DMH}$ hay grupos de neuronas específicas para cada uno de los diferentes órganos efectores de la RTF. Lo anterior parece cumplirse incluso en el rRPA, pues se ha visto que la referencia simpática que induce vasoconstricción en la piel glabra y velluda, es controlada de forma separada por al menos dos grupos de neuronas localizados en esta estructura (Romanovsky et al., 2009; Tanaka, Ootsuka, McKinley, \& McAllen, 2007).

\section{Las neuronas premotoras del rMR controlan a las neuronas de la médula espinal y estas a su vez a los órganos efectores}

Las neuronas premotoras simpáticas del rMR se proyectan a las neuronas preganglionares simpáticas de la columna celular intermedio lateral de la lámina VII de la médula espinal (IML) lo que causa un efecto excitatorio mediado por glutamato. A su vez, las neuronas preganglionares simpáticas de IML hacen sinapsis en la cadena paravertebral de ganglios simpáticos con neuronas postganglionares simpáticas (el neurotransmisor en esta sinapsis es acetilcolina). Estas últimas inervan directamente a los efectores de la termorregulación refleja y secretan noradrenalina (Tupone et al., 2014).

En el rMR hay también neuronas que se proyectan al asta ventral de la médula espinal y hacen sinapsis con las motoneuronas alfa y gama que proveen inervación motora a las fibras musculares extrafusales e intrafusales respectivamente, vía raíz ventral y nervio espinal; en estas sinapsis neuromusculares el neurotransmisor involucrado es acetilcolina (Meriney \& Dittrich, 2013). La activación resultante de las fibras musculares intrafusales ocasiona un incremento en las aferencias de las neuronas sensitivas tipo la del huso muscular, lo que a su vez refuerza la activación de las motoneuronas alfa por la vía del reflejo miotático. El mecanismo anterior finalmente -13 -

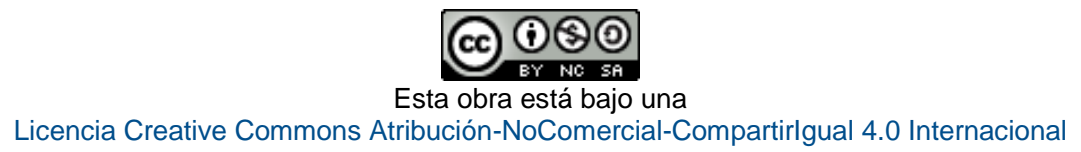


induce la fuerte contracción involuntaria de las fibras extrafusales que causa el típico tremor ante el frío que puede ser observado en registros electromiográficos (Morrison \& Nakamura, 2011; Morrison et al., 2008) y también a simple vista en sujetos que tienen frío.

\section{Efectores y respuestas}

Los mecanismos hipotalámicos del tallo y la médula espinal, anteriormente descritos, reclutan a los diferentes órganos efectores de la termorregulación refleja en función de los cambios detectados en la temperatura corporal. Aunque mucho se conoce sobre el rol de los efectores en la termorregulación, se hará énfasis únicamente en la información más esencial y en los avances más recientes.

El principal órgano efector de la termorregulación refleja son los vasos sanguíneos de la piel. Estos órganos son controlados por neuronas postganglionares simpáticas que cosecretan noradrenalina y neuropéptido $Y$ (a estas neuronas también se les conoce como el sistema adrenérgico), así como por neuronas postganglionares simpáticas que cosecretan acetilcolina con algún otro neurotransmisor no completamente determinado (a estas neuronas se les conoce también como sistema colinérgico, que adicionalmente es el responsable de la activación de las glándulas sudoríparas). La vasoconstricción cutánea es inducida por la contracción de las células del músculo liso vascular presentes en las arteriolas cutáneas, resultante de la activación del sistema adrenérgico. Por su parte, la vasodilatación ocurre por la relajación de las mismas células de músculo liso y puede ser inducida por una disminución de la actividad del sistema adrenérgico, en cuyo caso se denomina vasodilatación pasiva, o por una activación del sistema colinérgico, denominada vasodilatación neurogénica activa. Esta última ocurre solo en la piel no glabra (Simmons, Wong, Holowatz, \& Kenney, 2011).

En condiciones ambientales termoneutrales y a temperatura fisiológica normal existe un cierto grado de vasoconstricción cutánea basal, ya que las neuronas del rRPa tienen actividad excitatoria tónica, que genera activación permanente del sistema adrenérgico. A su vez, la actividad tónica de las neuronas del rRPa es modulada por la actividad tónica inhibitoria de las neuronas calientes de la MPO (ver sección Centro integrador hipotalámico) (Morrison \& Nakamura, 2011). De esta forma, la mayor parte del tiempo la temperatura corporal se conserva con solo pequeños aumentos o disminuciones del grado de activación del sistema adrenérgico, con su consecuente efecto en el grado de contracción de las células de músculo liso vascular, el flujo sanguíneo cutáneo y la eliminación de calor. Solo cuando estos cambios son insuficientes y la temperatura corporal se altera, se reclutan temporalmente otros mecanismos como la sudoración, la vasodilatación neurogénica activa en la piel no glabra o el tremor muscular, entre otros (Johnson \& Kellogg, 2010).

\section{Efectores activados ante un descenso de la temperatura corporal}




\section{Vasos sanguíneos cutáneos}

El descenso de la temperatura corporal induce vasoconstricción cutánea causada por un aumento del grado de activación del sistema adrenérgico y la activación resultante de los receptores alfa-1 de la célula de músculo liso vascular (Johnson \& Kellogg, 2010). Complementariamente, el enfriamiento de pequeñas zonas de la piel produce vasoconstricción exclusiva de la zona estimulada. Lo anterior involucra sin duda un mecanismo de tipo local, adicional al arco reflejo termorregulador, pues se da ante el enfriamiento de áreas de la piel tan pequeñas que no son capaces de modificar la temperatura del núcleo corporal y que no tienen efectos significativos sobre la actividad del centro integrador hipotalámico. Aunque el mecanismo que explica este fenómeno local no está completamente entendido, los experimentos demuestran que el frío local induce, entre otros fenómenos, un aumento local transitorio del número de receptores alfa adrenérgicos en las células de músculo liso vascular y una disminución en la producción local de óxido nítrico; fenómenos con efecto vasoconstrictor (Johnson \& Kellogg, 2010). Estos dos mecanismos vasoconstrictores cutáneos permiten retener calor corporal.

\section{Tejido adiposo pardo}

El tejido adiposo pardo posee un alto potencial termogénico aunque representa una baja proporción del peso corporal. Aunque por mucho tiempo se pensó que la relevancia fisiológica de este tejido estaba restringida a mamíferos pequeños solamente, la literatura reciente indica que éste es funcional en humanos adultos y que se activa en respuesta al frío (Hofmann, Elbelt, \& Stengel, 2014; López et al., 2013). Adicionalmente, se sabe que hay células de tejido adiposo blanco capaces de adoptar ciertas características del pardo (Hofmann et al., 2014). A este proceso se le denomina en inglés browning.

Durante la RTF, la secreción de norepinefrina de neuronas adrenérgicas que inervan el tejido adiposo pardo induce la activación de receptores beta-3, que regulan por la vía del AMPc la actividad de lipasas así como el nivel de expresión de la proteína desacoplante tipo 1 (proteína solo encontrada en este tejido) que causa fuga de protones a través de la membrana mitocondrial. Lo anterior produce un desacople entre la fosforilación oxidativa y la producción de ATP, lo que induce termogénesis (Clapham, 2012; López et al., 2013; Morrison et al., 2014; Morrison et al., 2008; Nakamura, 2011).

Se ha calculado que tan solo 50 gramos de tejido adiposo pardo activo es suficiente para causar un impacto positivo en el metabolismo y el peso corporal, lo que coincide altamente con las cantidades presentes en humanos que recientemente se han identificado, de 10 a $20 \mathrm{~g}$ (Clapham, 2012). Se ha hallado en los últimos años una relación inversamente proporcional entre la cantidad de tejido adiposo pardo y el índice de masa corporal y se ha propuesto la manipulación farmacológica de este tejido para combatir la obesidad (Cypess \& Kahn, 2010; Cypess et al., 2009). Además, durante la exposición al

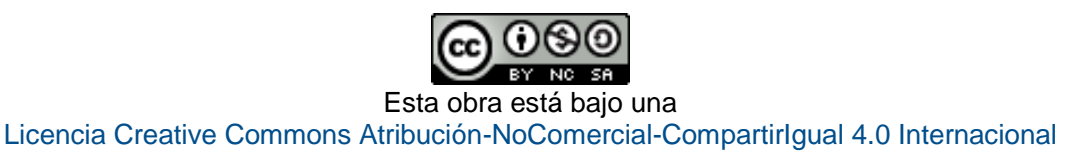


frío, este tejido aumenta su actividad, principalmente en sujetos jóvenes (23-35 años) y en menor medida en sujetos mayores (38 - 65 años) y obesos (Clapham, 2012).

\section{Corazón}

Metabólicamente hablando, el corazón es uno de los órganos más activos del cuerpo humano. Su consumo de oxígeno en reposo es de unos $0.1 \mathrm{~mL} \cdot \mathrm{g}^{-1} \cdot \mathrm{min}^{-1}$, lo que supera por mucho a otros órganos como el hígado $\left(0.02 \mathrm{~mL} \cdot \mathrm{g}^{-1} \cdot \mathrm{min}^{-1}\right)$, riñones $(0.06 \mathrm{~mL} \cdot \mathrm{g}$ $\left.{ }^{1} \cdot \mathrm{min}^{-1}\right)$ cerebro $\left(0.03 \mathrm{~mL} \cdot \mathrm{g}^{-1} \cdot \mathrm{min}^{-1}\right)$ piel $\left(0.003 \mathrm{~mL} \cdot \mathrm{g}^{-1} \bullet \mathrm{min}^{-1}\right)$ y músculo esquelético en reposo $\left.0.002 \mathrm{~mL} \cdot \mathrm{g}^{-1} \cdot \mathrm{min}^{-1}\right)$, así como al promedio de todo el cuerpo $\left(0.004 \mathrm{~mL} \cdot \mathrm{g}^{-1} \cdot \mathrm{min}^{-1}\right)$. Al tomar en cuenta que la masa del corazón promedia unos $300 \mathrm{~g}$, su consumo de

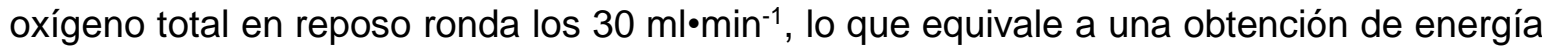
química equivalente a 600 Julios•min ${ }^{-1}$. De la cantidad anterior, menos de un $10 \%$ pasará a formar energía mecánica en forma de trabajo externo y el resto terminará formando calor (Barret, Barman, Boitano, \& Brooks, 2010; Boron \& Boulpaep, 2011; WitjasPaalberends et al., 2014). Al aplicar sencillos factores de conversión se puede expresar esta información en unidades de energía y tiempo más familiares: el corazón consume por día alrededor de $210 \mathrm{Kcal}$, de las cuales no menos de 185 se convierten en energía calórica. La conversión anterior coincide altamente con la predicción del gasto calórico del corazón humano obtenida a partir de modelos matemáticos, en los cuales se emplean datos de la utilización de sustratos de las principales vías metabólicas energéticas, obtenidos experimentalmente (Kummitha, Kalhan, Saidel, \& Lai, 2014).

La inervación simpática cardiaca produce taquicardia y aumento de la fuerza de contracción inducida por el efecto de la noradrenalina sobre los receptores beta-1 adrenérgicos y la vía del AMPc (Perino, Ghigo, Scott, \& Hirsch, 2012). Lo anterior aumenta la termogénesis cardiaca debido a la ineficiencia de la producción (fuga de protones de la membrana mitocondrial) y utilización (ciclo de puentes cruzados, recaptación de calcio hacia el retículo sarcoplasmático) muscular de ATP, pues ambos procesos, principalmente el segundo, liberan calor (Nakamura, 2011).

La taquicardia y el aumento de la fuerza de contracción cardiaca que se dan durante la RTF no solo generan calor, sino que contribuyen a distribuir hacia otros tejidos el calor generado en el corazón, en el tejido adiposo y en el músculo esquelético y simultáneamente provee a estos tres efectores con nutrientes que satisfacen el aumento de su metabolismo en estas circunstancias (Morrison \& Nakamura, 2011; Morrison et al., 2008; Nakamura, 2011).

Información reciente indica que el ejercicio y la exposición al frío causan un aumento en la producción cardiaca de péptido atrial natriurético; péptido con acción endocrina tradicionalmente ligado a la homeostasis de la presión arterial y el volumen circulante efectivo. Sin embargo, lo más interesante es el reciente descubrimiento de que el péptido citado induce lipólisis en el tejido adiposo, activación del tejido adiposo pardo y browning del tejido adiposo blanco, además de estimular la biogénesis mitocondrial y la 
expresión de proteína desacoplante 1, entre otros efectos. Todo lo anterior aumenta la termogénesis, de forma que el corazón de un sujeto que está expuesto al frío no solo aumenta su termogénesis propia, sino que la induce en otros órganos especializados a tal efecto. Es interesante que en sujetos obesos y diabéticos la producción cardiaca de péptido atrial natriurético está disminuida (Collins, 2014). Nótese la interacción entre termoregulación, balance energético y control de la presión arterial en este caso.

\section{Músculo esquelético}

En el músculo esquelético, la termogénesis por tremor se origina a partir de la ineficiencia en la producción y utilización de ATP, como ocurre en el músculo cardiaco (Morrison \& Nakamura, 2011; Morrison et al., 2008). El músculo esquelético es el último efector que es reclutado en la RTF y esto ocurre si la temperatura corporal sigue descendiendo a pesar de la activación de la taquicardia, la termogénesis en el tejido adiposo pardo y la vasoconstricción de los vasos sanguíneos cutáneos. Lo anterior respalda la idea de la existencia de distintas poblaciones de neuronas calientes del POA, controladoras de efectores de la RTF por vías nerviosas eferentes paralelas. Este mecanismo sería evolutivamente ventajoso, al tomar en cuenta el alto costo energético y la vulnerabilidad ante depredadores o peligros que el tremor muscular implica (Morrison \& Nakamura, 2011). La activación de este efector está dada por el efecto de las neuronas del rMR sobre las motoneuronas alfa y gamma de las astas ventrales de la médula espinal, descrito en el apartado anterior.

\section{Efectores activados ante un aumento de la temperatura corporal}

\section{Vasos sanguíneos cutáneos}

Normalmente, la vasodilatación cutánea inducida por el aumento de la temperatura corporal ocurre de forma pasiva, por inactivación del sistema adrenérgico causante de vasoconstricción en la piel. Pero cuando la temperatura ambiental y la generación metabólica de calor exceden la capacidad de pérdida de calor mediada por la vasodilatación pasiva (como ocurre durante ejercicio), otros mecanismos y órganos efectores son reclutados, como la vasodilatación neurogénica activa en la piel no glabra y sudoración (Johnson \& Kellogg, 2010; Kellogg, Zhao, Wu, \& Johnson, 2012). Se ha estimado que el sistema colinérgico es responsable de entre el $80 \%$ y $95 \%$ de incremento del flujo sanguíneo cutáneo durante un desafío térmico significativo (Kellogg et al., 2012), como en el ejercicio.

El aumento de la temperatura en áreas muy pequeñas de la piel de forma local también induce vasodilatación exclusiva de la zona estimulada. La caracterización del mecanismo fisiológico que explicaría esta reacción aún requiere investigación experimental, aunque se sabe que los termorreceptores que expresan los canales TRP

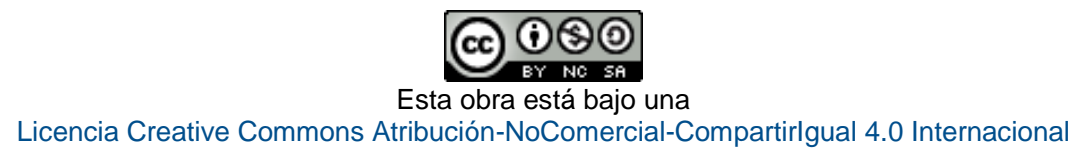


están involucrados, así como la producción de óxido nítrico, conocido vasodilatador (Johnson \& Kellogg, 2010).

\section{Glándulas sudoríparas}

La sudoración inicia cuando la disminución de la actividad vasoconstrictora del sistema adrenérgico en la piel no es suficiente para neutralizar el aumento de la temperatura corporal y su activación tiende a coincidir con la activación de la vasodilatación neurogénica activa. Esto ha hecho que se piense que el mecanismo nervioso que activa a la glándula sudorípara es el mismo que activa a este tipo de vasodilatación. La posibilidad anterior, no obstante, ha sido objetada de varias maneras (Johnson \& Kellogg, 2010).

En la piel, el sudor es un mecanismo efectivo de liberación de energía térmica, aunque puede aumentar significativamente la osmolalidad del plasma y disminuir el volumen sanguíneo, procesos contraproducentes para la termorregulación refleja. La osmolalidad plasmática aumentada tiene efectos centrales que producen un aumento en el umbral de temperatura corporal capaz de inducir sudoración y vasodilatación (Lynn, Gagnon, Binder, Boushel, \& Kenny, 2012; Morrison et al., 2008). Por su parte, la hipovolemia compromete la adecuada perfusión de los tejidos y con ello el transporte de energía calórica de órganos que generan calor (músculo esquelético activo) a órganos que la disipan (piel y glándulas sudoríparas), además de elevar el umbral térmico que da inicio a la sudoración y la vasodilatación cutánea y disminuir la pendiente de la relación aumento de la temperatura corporal / aumento de la sudoración (Shibasaki \& Crandall, 2010). Todos estos fenómenos limitan la RTC (Lynn et al., 2012; Shibasaki, Wilson, \& Crandall, 2006).

Estudios efectuados en primates no humanos han demostrado que la sudoración es primeramente controlada por la temperatura del núcleo corporal (considerada la variable principal de la termorregulación refleja), especialmente la del cerebro, y es modulada por la temperatura de la piel (variable auxiliar). De hecho, el concepto de temperatura corporal media se deriva de este tipo de estudios y consiste en última instancia en una suma ponderada de ambas variables (Shibasaki \& Crandall, 2010; Shibasaki et al., 2006).

Las neuronas posganglionares simpáticas que inervan a las glándulas sudoríparas son principalmente colinérgicas, por lo que la acetilcolina es el principal neurotransmisor que induce la sudoración (Vinik, Nevoret, Casellini, \& Parson, 2013; Shibasaki \& Crandall, 2010). Además, una pequeña porción de la inervación de las glándulas sudoríparas parece ser adrenérgica, aunque esta juega un rol secundario (Harker, 2013). Otras moléculas son moduladoras de la sudoración, entre ellas el péptido intestinal vasoactivo, el péptido relacionado con el gen de calcitonina, el óxido nítrico y la sustancia P (Harker, 2013; Shibasaki \& Crandall, 2010). La tasa de sudoración también puede ser modulada por factores no térmicos tales como el comando central, el reflejo presor del ejercicio, el

$-18-$

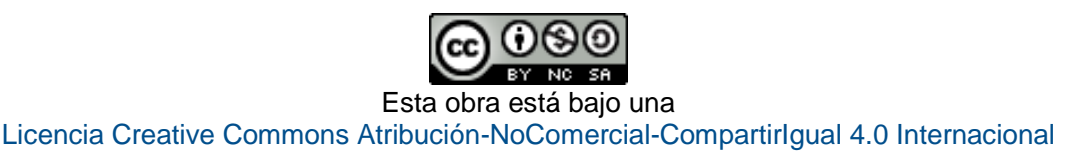


movimiento articular y muscular y el reflejo orofaríngeo (Shibasaki \& Crandall, 2010; Shibasaki et al., 2006).

Finalmente, las glándulas sudoríparas también son influenciadas por la temperatura local de la piel, pues sus aumentos y disminuciones causan variaciones de la producción de sudor específicamente en la zona estimulada. Esto se puede deber a influencias de la temperatura local sobre la tasa de liberación de neurotransmisores y la sensibilidad de los receptores de las glándulas ante ellos (Shibasaki et al., 2006).

\section{Corazón}

Como parte de la RTC suele observarse taquicardia inducida por una disminución del tono vagal. Esto hace pensar que esta respuesta está mediada por el baroreflejo, que reacciona incluso ante ligeras disminuciones de la presión arterial media inducidas por disminuciones de la presión venosa central resultante de una fuerte vasodilatación cutánea (Morrison \& Nakamura, 2011). No obstante, dentro de la RTC existe taquicardia refleja que depende de la activación de las neuronas del LPBd, aunque las conexiones desde esta estructura hasta el resto del sistema nervioso central no están claras aún (Nakamura, 2011). La figura 3 ilustra el reclutamiento de los diferentes órganos efectores de la termorregulación refleja en función de la intensidad del desafío térmico presente y según el costo energético de su trabajo, gracias a las vías nerviosas eferentes paralelas que los inervan.

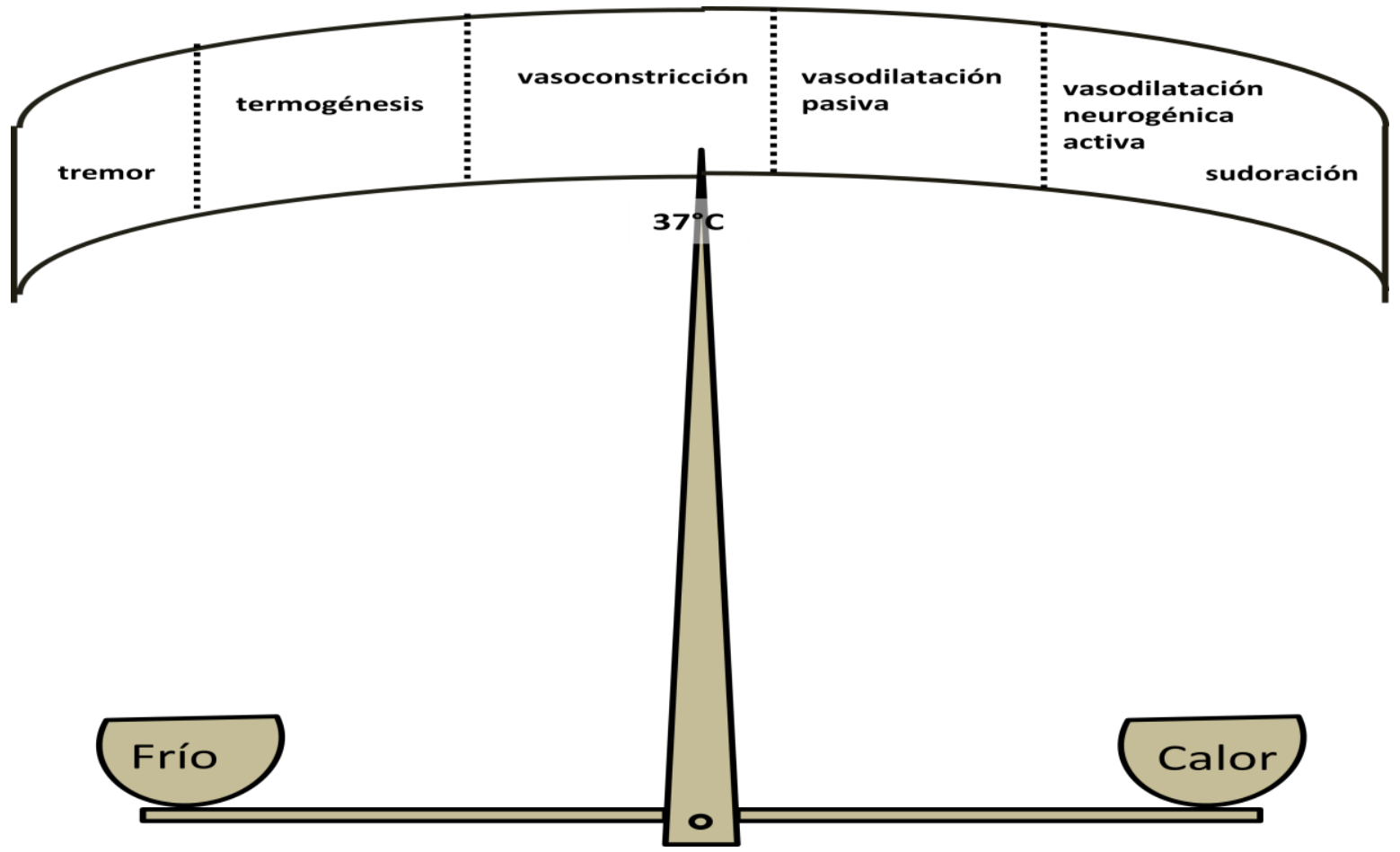

Figura 3. Reclutamiento escalonado de los órganos efectores de la termorregulación refleja. A $37^{\circ} \mathrm{C}$ existe vasoconstricción tónica inducida por el sistema adrenérgico. El aumento de la temperatura corporal induce sucesivamente una disminución de la vasoconstricción que resulta en vasodilatación pasiva, reclutamiento del sistema colinérgico que induce vasodilatación -19 - 
neurogénica activa y activación de la sudoración. Una disminución de la temperatura corporal induce un incremento en la vasoconstricción, activación de la termogénesis en varios tejidos y en última instancia tremor muscular. Entre la vasodilatación neurogénica activa y la sudoración no hay una línea divisoria, pues estas dos respuestas tienden a activarse de manera simultánea. Las líneas discontinuas indican que entre cada respuesta no hay una temperatura exacta ni una activación súbita, sino una transición paulatina. Tanto el aumento como la disminución de la temperatura corporal inducen taquicardia (no representado). Fuente: elaboración propia a partir de información disponible en (Morrison \& Nakamura, 2011; Morrison et al., 2008; Nakamura, 2011; Romanovsky et al., 2009)

\section{Termorregulación por conducta o comportamiento}

\section{Generalidades}

Todos los mecanismos hasta ahora expuestos son claramente de tipo reflejo. No obstante, en los últimos años ha cobrado importancia la investigación de la llamada termorregulación por conducta, dada por decisiones voluntarias de los individuos. Ejemplos de este tipo de termorregulación incluyen elegir el tipo de vestimenta, buscar o evitar el sol o el viento, hidratarse, cambiar la posición del cuerpo o la postura e incluso disminuir o aumentar la intensidad del ejercicio en función de las circunstancias, entre otros ejemplos similares (Flouris, 2011; Schlader, Stannard, \& Mündel, 2010; Terrien, Perret, \& Aujard, 2011). Este tipo de termorregulación no se ajusta al esquema del arco reflejo, pues aunque se pueden mencionar estímulos, vías aferentes y receptores involucrados, no existe un centro integrador como tal, con funcionamiento automático. La información aferente es enviada en última instancia a un órgano de control superior y voluntario, dado principalmente por la corteza cerebral, que continuamente toma decisiones. La información térmica percibida, influencia las decisiones del individuo, pero no las determina por completo, pues estas claramente dependen adicionalmente de muchas otras fuentes de información. Además, estas decisiones no son estereotipadas, automáticas e involuntarias y no necesariamente son inmediatas, como es característico de las respuestas de un arco reflejo orquestado por un centro integrador. La figura 4 presenta una visión conjunta e integrativa de los dos tipos de termorregulación existentes.

\section{Comparaciones entre termorregulación de conducta y termorregulación refleja}

La termorregulación refleja se ve activada cuando se dan estímulos térmicos que modifican la temperatura de la periferia o del núcleo corporal y no requiere de percepción térmica consciente en la mente de los individuos (de hecho, como depende del hipotálamo, funciona por igual en individuos sanos conscientes e individuos dormidos o incluso inconscientes debido a daño en la corteza cerebral). La termorregulación de conducta se puede dar igualmente ante la presencia de estímulos térmicos, pero también antes de que ellos se presenten (alguien puede ponerse un abrigo antes de salir de su casa), su activación requiere indispensablemente de la percepción consciente del individuo de perder el confort térmico, o de saber que lo va a perder y no necesariamente requiere de alteraciones de la temperatura de la periferia y del núcleo corporal (depende 
altamente de la corteza cerebral y necesariamente requiere que el sujeto esté consciente) (Flouris, 2011; Schlader, Simmons, Stannard, \& Mündel, 2011). Lo anterior se demuestra experimentalmente cuando los animales con lesiones en la región preóptica del hipotálamo prácticamente pierden toda su capacidad de ejercer termorregulación refleja, pero conservan prácticamente intacta la termorregulación de conducta (Nagashima, 2006; Romanovsky et al., 2009). Por otro lado, los ratones con lesión en el tálamo (ver aferencias en la sección siguiente), e incluso con remoción experimental de la neocorteza cerebral, pierden la termorregulación de conducta, pero conservan la refleja si el hipotálamo está intacto (Morrison et al., 2008; Nakamura, 2011) 


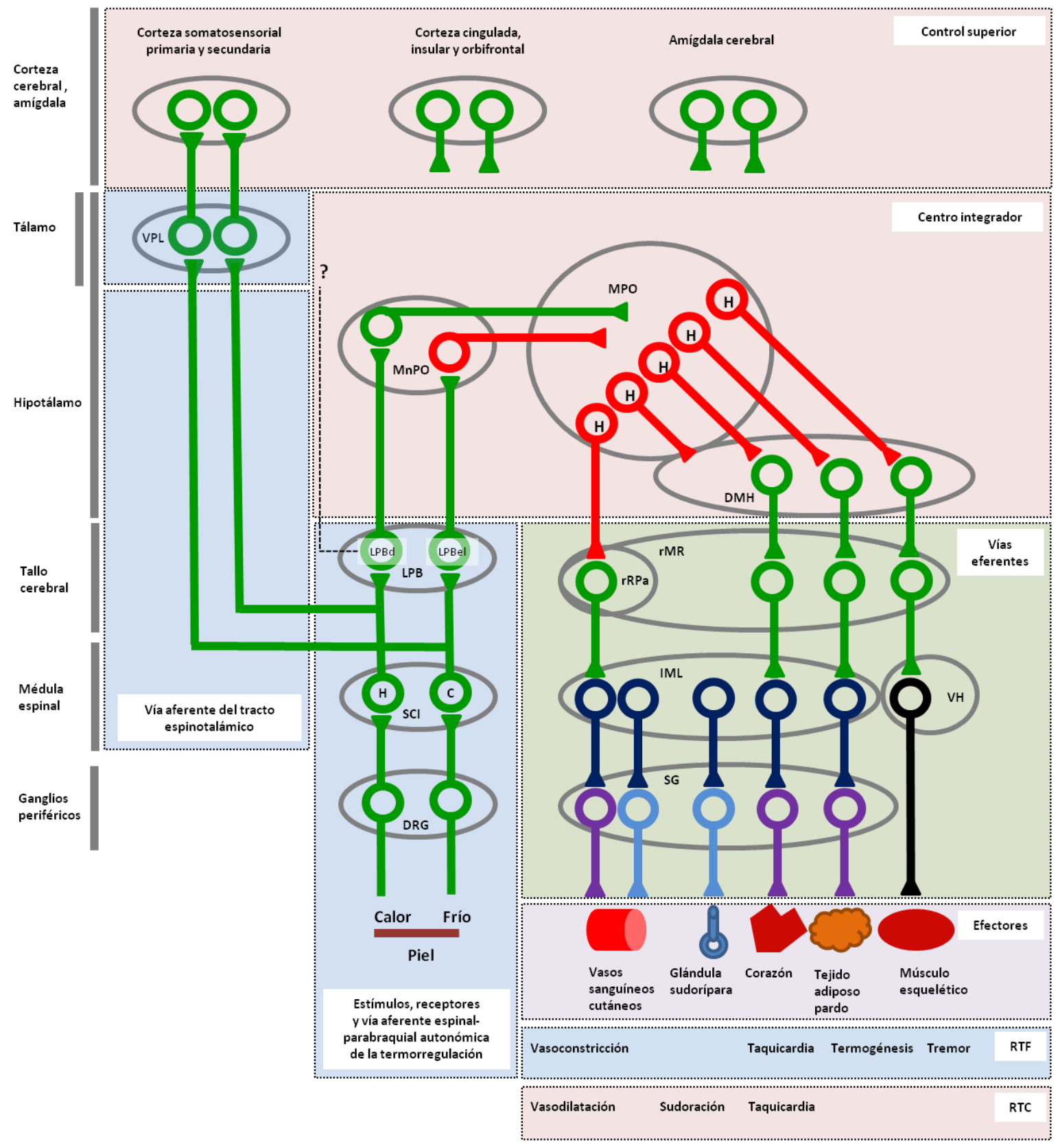

Figura 4. Representación esquemática de la termorregulación refleja y de conducta. Se incluye toda la información de la figura 2 (termorregulación refleja) y se añade la información referente a la termorregulación por conducta (parte izquierda y superior). En las vías añadidas se representan de color verde las neuronas secretoras de glutamato. Nótese como la neurona aferente primaria y secundaria es común para las vías aferentes de ambos sistemas. En la corteza cerebral existen muchos otros tipos de neuronas que no han sido representadas por falta de espacio. Las vías aferentes de la cara no se representan por falta de espacio. VPL: núcleo ventral posterior lateral del tálamo. Fuente: elaboración propia a partir de la información disponible en (Flouris, 2011; Nagashima, 2006; Purves et al., 2012; Schlader et al., 2011; Schlader et al., 2010; Terrien et al., 2011), además de las fuentes de la figura 2. 
La efectividad de la termorregulación refleja está dada por la capacidad de los órganos efectores de perder o ganar calor, capacidad que es limitada y puede ser insuficiente en casos extremos (ejemplos de esto son el fallecimiento por hipotermia o hipertemia en ambientes extremos). La termorregulación de conducta por su parte, depende de decisiones voluntarias para evitar o buscar el calor. Estas decisiones pueden evitar del todo o en gran medida la modificación de la temperatura de la periferia y del núcleo corporal y la necesidad de la activación de la termorregulación refleja y sus órganos efectores, lo que además ahorra energía. Esto hace que muchos autores consideren a la termorregulación de conducta incluso de mayor eficiencia e importancia para la conservación de la homeostasis térmica (Flouris, 2011; Schlader et al.,_2010; Terrien et al., 2011). Lo anterior no obstante es debatible, pues si la termorregulación de conducta depende de las decisiones del sujeto, esta puede ser voluntariamente reprimida (alguien podría optar por no detenerse en un puesto de asistencia a beber agua en una competencia, o usar trajes calientes o vestimenta inadecuada mientras se ejercita, decidir hacer un recorrido por el desierto, o nadar en aguas frías, etc.), mientras que la termorregulación refleja se activará siempre de forma automática, independientemente de lo que la voluntad del individuo pudiera determinar.

\section{conducta \\ Estímulos, receptores y aferencias que influencian la termorregulación de}

Aunque los estímulos y receptores implicados en ambos tipo de termorregulación son los mismos (ver sección Estímulos, así como sección Receptores), la vía aferente es diferente en cada caso. Mientras que en la termorregulación refleja la información térmica es enviada hacia el hipotálamo por la vía espinal-parabraquial autonómica ya descrita, en la termorregulación de conducta la información térmica es enviada hasta la corteza somatosensorial cerebral por el tracto espinotalámico lateral (Flouris, 2011; Purves et al., 2012). La información térmica detectada por los termoreceptores cutáneos de frío y de calor inocuos es transmitida inicialmente por estas neuronas aferentes primarias somatosensoriales, cuyo soma se ubica en los ganglios de la raíz dorsal. El axón de estas neuronas ingresa por los nervios espinales y la raíz dorsal hasta la lámina 1 de las astas dorsales de la médula espinal ipsilateral, donde establece sinapsis excitatorias con neuronas aferentes secundarias. Hasta este punto, la vía espinal-parabraquial autonómica y el tracto espinotalámico lateral forman un tronco común. Posteriormente, las neuronas aferentes secundarias de la lámina I del asta dorsal tienen ramificaciones que decusan la línea media corporal, ascienden por la zona lateral de la médula espinal, continúan su ascenso por el tallo cerebral y establecen sinapsis excitatorias con neuronas aferentes terciarias en el núcleo ventral posterior lateral del tálamo. Estas últimas neuronas también son excitatorias y se proyectan a los lóbulos parietales del giro postcentral cerebral donde se ubica la corteza somato-sensorial primaria, de donde la información puede proyectarse a otras áreas corticales (Purves et al., 2012). En el caso de la cara, la información térmica 
detectada por los termorreceptores, será transportada por estas neuronas aferentes primarias del nervio trigémino, que se extienden hasta el núcleo espinal de este par craneal en la médula oblongada, donde establecerán sinapsis excitatorias con neuronas aferentes secundarias (de nuevo, hasta aquí la vía aferente es común con la vía espinalparabraquial autonómica). Estas últimas neuronas a su vez tienen ramas que cruzan la línea media del cuerpo y ascienden hasta el núcleo ventral posterior medial del tálamo, donde establecen sinapsis excitatorias con neuronas aferentes terciarias que se proyectan igualmente hasta la corteza cerebral (Purves et al., 2012). A esta última vía se le llama también tracto trigémino-talámico.

Cuando la información térmica llega a la corteza cerebral, el individuo percibirá de forma consciente las sensaciones de frío y de calor, lo que influenciará su toma de decisiones con respecto a la termorregulación por conducta. Algunas de las áreas cerebrales que se activan cuando se toman este tipo de decisiones incluyen la corteza somatosensorial primaria y secundaria, corteza cerebral cingulada, insular y orbitofrontal. Otras regiones cerebrales que posiblemente están involucradas en este tipo de termorregulación son la amígdala cerebral, varias partes del tallo cerebral y el hipotálamo dorsomedial; nótese que estas últimas dos estructuras también participan en la termorregulación refleja, aunque no necesariamente con las mismas neuronas (Flouris, 2011).

\section{Termorregulación de conducta y refleja en el contexto del ejercicio}

Según se expuso en la sección referente a las glándulas sudoríparas, la termorregulación refleja se ve disminuida ante deshidratación y aumento de la osmolalidad del plasma, fenómenos que ocurren durante ejercicio. No obstante, la termorregulación por conducta más bien se ve aumentada ante tales circunstancias. En ratas y otros animales se ha demostrado experimentalmente que la deshidratación y el aumento de osmolalidad del plasma aumentan la termorregulación por conducta, lo que es evidenciado, por ejemplo, por la elección voluntaria de lugares fríos (Konishi, Nagashima, \& Kanosue, 2002; Nagashima, 2006; Nagashima, Nakai, Konishi, Su, \& Kanosue, 2001). Conductas similares a las mencionadas claramente se presentan en sujetos humanos deshidratados al final de una competencia atlética. Lo anterior también se sustenta por evidencia experimental que sugiere que la deshidratación moderada y la temperatura corporal aumentada por ejercicio en el calor en humanos, afectan negativamente la termorregulación refleja, pero no limitan la termorregulación de conducta (Schlader et al., 2011; Schlader et al., 2010; Tokizawa et al., 2010).

Finalmente, se debe subrayar que ambos tipos de termorregulación son en última instancia controlados por neuronas, cuyas bases moleculares de funcionamiento son comunes. Por esto no es de extrañar que la deshidratación y la consecuente osmolalidad aumentada del plasma, cuando alcanzan valores extremos, sí son capaces de afectar negativamente a la termorregulación de conducta, tal y como sucede con la refleja -24 -

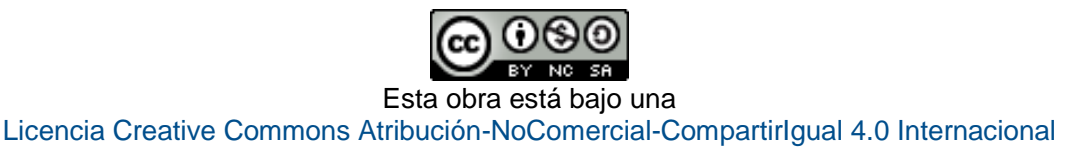


(Konishi, Nagashima, Asano, \& Kanosue, 2003; Lin et al., 2012). Lo anterior ilustra la importancia de no oponerse voluntariamente durante ejercicio a la termorregulación de conducta, pues puede llegar el momento en que sea demasiado tarde.

Según lo expuesto, durante el ejercicio, la adecuada hidratación así como el hecho de prestar atención al grado de confort térmico percibido, favorecería el mantenimiento de la homeostasis térmica. En el contexto competitivo, las circunstancias pueden limitar los diferentes mecanismos de termorregulación y sería ventajoso diseñar estrategias que minimicen estas desventajas.

\section{Lo que queda por aprender}

Se ha visto que el LPB no solo recibe aferencias provenientes de los termorreceptores, sino también de información visceral como tensión gástrica, sabor, saciedad, sed, presión arterial, entre otros, lo que sugiere que esta estructura integra la información térmica somática con información visceral antes de enviarla hacia la POA. La POA por su parte es un centro integrador que no solamente tiene función termorreguladora, sino que controla muchos otros procesos homeostáticos que a primera vista no parecen relacionados con la termorregulación, tal vez porque aún no los entendemos (Morrison et al., 2008; Nakamura, 2011).

La mezcla de aferencias de la termorregulación refleja con otras señales no térmicas podría según algunos, constituir una conexión entre órganos que suplen al cuerpo con energía (tracto gastrointestinal y otros) y los órganos que la disipan (vasos sanguíneos, tejido adiposo pardo, entre otros). La evidente mezcla existente entre el sistema termorregulador y otros mecanismos se ilustra claramente por medio de conocidos reflejos: a) la distención estomacal produce cambios en la termogénesis del tejido adiposo pardo, b) lo anterior también es inducido por la presencia de glucosa intraportal y por la presencia de solución salina hipertónica, así como por la presencia de lípidos en el duodeno y c) la distensión colorectal produce vasoconstricción cutánea, fenómeno presente en la RTF (Morrison et al., 2014; Romanovsky et al., 2009).

Cada vez existe más evidencia de efectos de diferentes señales endocrinas relacionadas con la composición corporal y el balance energético (leptina, insulina, glucosa, orexina y otros) sobre las neuronas de los núcleos de la termorregulación refleja (MnPO, MPO, DMH, rRPA, IML y otros). Estos mecanismos centrales, en combinación con la descrita integración entre señales aferentes térmicas y metabólicas (ver sección Mecanismos integradores en el área preóptica medial), hace que actualmente aumente el consenso sobre una regulación integrada de termorregulación refleja, metabolismo, balance energético y composición corporal, aunque la clara explicación de estas interacciones apenas inicia (Morrison et al., 2014; Tupone et al., 2014). Un ejemplo que ilustra lo anterior es el factor circulante tipo meteorina (Metrnl) hormona recientemente descubierta que se produce en el músculo esquelético durante ejercicio y en el tejido adiposo durante la exposición al frío. El aumento de los niveles circulantes de Metrnl 
aumenta el gasto energético por activación de la termogénesis, además de que mejora la tolerancia a la glucosa. Su rol evidente en la homeostasis de la temperatura corporal, balance energético y metabolismo, la presenta como una potencial herramienta terapéutica para sujetos obesos (Rao et al., 2014). Nótese que los estímulos que inducen secreción de Metrnl en el músculo esquelético y tejido adiposo (ejercicio y frío, respectivamente) también inducen secreción de péptido atrial natriurético en el corazón, y que tanto Metrnl como este péptido activan la termogénesis (ver sección Corazón, en órganos efectores de la termorregulación refleja activados ante un descenso de la temperatura corporal). Entonces estos estímulos diversos actúan en varios órganos efectores e inducen la producción de señales químicas distintas que generan un efecto final común. Todo esto ilustra una vez más la regulación integrada de la termorregulación refleja, metabolismo, balance energético y composición corporal mencionada anteriormente.

Por todo lo anterior, y debido a que la termogénesis refleja implica un elevado gasto energético y un uso aumentado de sustratos energéticos (glucosa, ácidos grasos), la manipulación farmacológica de este arco reflejo supone en el futuro una buena oportunidad de control del peso, la composición corporal, la diabetes y otras enfermedades metabólicas (Wu, Cohen, \& Spiegelman, 2013). De hecho, existen varios fármacos con posibles efectos antiobesidad, que en el futuro podrían funcionar adecuadamente al influenciar este arco reflejo (Clapham, 2012).

La mayoría de los órganos efectores que participan en la RTF y RTC cumplen otras funciones que en caso del corazón y el músculo esquelético resultan obvias. El tejido adiposo pardo por su parte, juega un rol importante en la regulación metabólica de la energía almacenada mientras que los vasos sanguíneos cutáneos producen vasoconstricción ante hipovolemia, por mencionar algunos otros ejemplos. Por lo anterior, uno de los aspectos más intrigantes es la resolución de los conflictos que necesariamente surgen cuando los órganos efectores cumplen varias funciones (Morrison \& Nakamura, 2011). Si una persona se deshidrata extremadamente por ejercitarse de manera prolongada en el calor, el arco reflejo de la termorregulación entra en conflicto con el de la regulación de la presión arterial, pues la vasodilatación cutánea termorreguladora tiene un efecto aditivo sobre la caída de la presión arterial inducida por la hipovolemia, mientras que la vasoconstricción cutánea permitiría mantener la presión arterial en valores más cercanos a su punto de ajuste, aunque la temperatura del cuerpo se alejaría del suyo. Algunos estudios sugieren que en ejercicio intenso en el calor el flujo sanguíneo en la piel se ve reducido a expensas de suministrar sangre y oxígeno al músculo esquelético (el gasto cardiaco no es suficiente para los dos órganos) (Simmons et al., 2011). Cómo, cuándo y dónde el sistema nervioso central establece las prioridades en este tipo de conflictos es algo que no se ha explicado experimentalmente al día de hoy.

Los mecanismos reflejos descritos en esta revisión son capaces de explicar la inhibición del sistema adrenérgico cutáneo que se da inicialmente, como parte de la RTC.

$-26-$

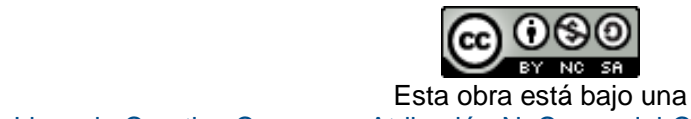

Licencia Creative Commons Atribución-NoComercial-Compartirlgual 4.0 Internacional 
No obstante, ninguno de los mecanismos descritos para la RTC explica claramente cómo ocurre en los circuitos del sistema nervioso central, el reclutamiento del sistema colinérgico cutáneo, que induce la vasodilatación neurogénica activa y la sudoración cuando la temperatura corporal sigue aumentando. Además, cuando la temperatura corporal aumenta también se observa una vasoconstricción visceral que reduce el flujo sanguíneo en zonas esplácnicas y renales, que posiblemente favorece la redistribución del flujo sanguíneo hacia la piel (Morrison \& Nakamura, 2011). Tampoco se conoce de forma exacta el mecanismo del sistema nervioso central que recluta a las neuronas que generan este último fenómeno.

Es bien sabido que es posible adaptar la RTC al ejercicio en climas cálidos. Unas siete sesiones de ejercicio (incluso menos) en el calor son suficientes para inducir aumento del flujo sanguíneo en la piel para una dada temperatura corporal con disminución del umbral de temperatura corporal que activa la vasodilatación y sudoración. Un fenómeno como el anterior se conoce en fisiología como un aumento de la ganancia de un arco reflejo y consiste en una mejor sensibilidad ante el estímulo, un aumento concomitante de las respuestas y un mejor grado de control de la variable regulada. Este tipo de adaptaciones genera una menor temperatura corporal durante ejercicio en el calor, fenómeno conocido como aclimatación (Chalmers, Esterman, Eston, Bowering, \& Norton, 2014). No obstante, la naturaleza de las modificaciones en el funcionamiento de las principales neuronas del centro integrador y de los otros núcleos nerviosos involucrados en la RTC (las presentes en la figura 2), que explicarían estos cambios, son hasta la fecha muy vagamente conocidas.

Finalmente, existen áreas adicionales del sistema nervioso central involucradas en la termorregulación refleja, tales como el locus ceruleus, el núcleo paraventricular del hipotálamo y algunas regiones del mesencéfalo, entre otros. No obstante, no es del todo clara la forma en que estos núcleos establecen circuitos nerviosos con el centro integrador de la termorregulación refleja (nótese que estas estructuras están ausentes en la figura 2). Por otra parte, de forma excepcional, algunas neuronas del MnPO parecen estar involucradas en la termorregulación de conducta, aunque de forma muy limitada. Estas conexiones no están claramente explicadas, como no lo están para otras estructuras nerviosas involucradas en este tipo de termorregulación (Romanovsky et al., 2009).

Muchos estudios experimentales han examinado estas y otras aristas de la termorregulación y con toda seguridad muchos más vendrán. Por lo pronto, este es el escenario general.

\section{Conclusiones}

Los avances recientes en la comprensión de la termorregulación han sido posibles gracias al uso intensivo de nuevos recursos tecnológicos y la participación de profesionales del área de las neurociencias, la fisiología básica y la fisiología del ejercicio, 
entre otros. Los descubrimientos efectuados tienen gran potencial en un sinnúmero de manipulaciones útiles de los mecanismos termorreguladores, entre las que destacan: a) el control del metabolismo y la composición corporal en pacientes obesos, a través de estrategias farmacológicas y de protocolos de ejercicio, b) el control asistido de la temperatura corporal en sujetos con lesiones del sistema nervioso central o sometidos a protocolos de anestesia que en ciertos casos pueden alterar la termorregulación, c) la inducción y el control exitosos de hipotermia terapéutica, una estrategia efectiva para reducir la fiebre, así como evitar lesiones cerebrales y cardiacas ante isquemia sistémica por fallas cardiacas (pues la hipotermia reduce la demanda metabólica de oxígeno) y que puede complicarse por la activación de la RTF y d) por supuesto, el rendimiento deportivo, que supone un desafío térmico que lleva a estos procesos homeostáticos hasta sus límites.

Los diferentes protocolos de actividad física implican alteraciones de la temperatura en el núcleo y la periferia corporal y del confort térmico en diversas formas, en función de factores ambientales, de la naturaleza del deporte practicado, de la indumentaria utilizada, entre otros. Por esta razón, la comprensión del funcionamiento de los diferentes mecanismos termorreguladores contribuye junto con el conocimiento de otras disciplinas, a que el profesional en el movimiento humano pueda razonar y justificar decisiones relacionadas con la prescripción de ejercicio, las condiciones de competencia y los protocolos de rehidratación. Por ejemplo, se ha observado que el simple hecho de vestir una camiseta adicional por debajo del uniforme, causa un aumento significativo del grado de deshidratación durante un partido de fútbol en sujetos no profesionales (LópezDávila, 2014).

Finalmente, debido a que la actividad física aumenta la temperatura corporal, su uso controlado y sistemático en modelos animales y humanos es un recurso experimental valioso, que está a disposición de los fisiólogos del ejercicio. Esta herramienta puede aportar nuevos descubrimientos en la comprensión de los diferentes mecanismos termorreguladores, e incluso en su poco caracterizada integración neural con otros procesos homeostáticos simultáneamente activados por la actividad física, como lo son los cardiovasculares, respiratorios, energéticos y metabólicos, entre otros.

\section{Referencias}

Barret, K., Barman, S., Boitano, S., \& Brooks, H. (2010). Ganong. Fisiología Médica (23a ed.). México D.F.: McGraw-Hill. Recuperado de: http://mcgraw-hill.com.mx/cgibin/book.pl?isbn=00000038MX\&division=mexh

Belmonte, C., \& Viana, F. (2008). Molecular and cellular limits to somatosensory specificity. Molecular Pain, 4, 14. Recuperado de: http://www.molecularpain.com/content/4/1/14 doi: 10.1186/1744-8069-4-14. 
Bharate, S. S., \& Bharate, S. B. (2012). Modulation of thermoreceptor TRPM8 by cooling compounds. ACS Chemical Neuroscience, 3(4), 248-267. Recuperado de: http://pubs.acs.org/doi/abs/10.1021/cn300006u doi: $10.1021 / \mathrm{cn} 300006 \mathrm{u}$

Boron, W., \& Boulpaep, E. (2011). Medical Physiology (2 $2^{\text {da }}$ ed.). Philadelphia: Saunders. Recuperado de: http://store.elsevier.com/Medical-Physiology-2e-Updated-EditionE-Book/Walter-Boron/isbn-9781455711819/

Chalmers, S., Esterman, A., Eston, R., Bowering, K. J., \& Norton, K. (2014). Short-Term Heat Acclimation Training Improves Physical Performance: A Systematic Review, and Exploration of Physiological Adaptations and Application for Team Sports. Sports Medicine. Recuperado de: http://link.springer.com/article/10.1007/s40279$\underline{014-0178-6}$ doi: $10.1007 / \mathrm{s} 40279-014-0178-6$

Clapham, J. C. (July, 2012). Central control of thermogenesis. Neuropharmacology, 63(1), 111-123. doi: http://dx.doi.org/10.1016/j.neuropharm.2011.10.014

Clarac, F. (January, 2008). Some historical reflections on the neural control of locomotion. Brain Research Reviews, 57(1), 13-21. Recuperado de: http://www.sciencedirect.com/science/article/pii/S0165017307001324 doi: 10.1016/j.brainresrev.2007.07.015

Collins, S. (March, 2014). A heart-adipose tissue connection in the regulation of energy metabolism. Nature Reviews Endocrinology, 10(3), 157-163. Recuperado de: http://www.nature.com/nrendo/journal/v10/n3/full/nrendo.2013.234.html doi: 10.1038/nrendo.2013.234

Cypess, A. M., \& Kahn, C. R. (August, 2010). The role and importance of brown adipose tissue in energy homeostasis. Current Opinion in Pediatrics, 22(4), 478-484. Recuperado de: http://journals.Iww.com/copediatrics/Abstract/2010/08000/The role and importance of brown adipose tiss ue in.16.aspx doi:10.1097/MOP.0b013e32833a8d6e

Cypess, A. M., Lehman, S., Williams, G., Tal, I., Rodman, D., Goldfine, A. B., . . Kahn, C. R. (2009). Identification and importance of brown adipose tissue in adult humans. New England Journal of Medicine, 360, 1509-1517. Recuperado de: http://www.nejm.org/doi/full/10.1056/NEJMoa0810780 doi: 10.1056/NEJMoa0810780

Dhaka, A., Viswanath, V., \& Patapoutian, A. (2006). Trp ion channels and temperature sensation. Annual Review of Neuroscience, 29, 135-161. Recuperado de: http://www.annualreviews.org/doi/abs/10.1146/annurev.neuro.29.051605.112958 doi: 10.1146/annurev.neuro.29.051605.112958 
Fahlke, C., Linke, W., Raßler, B., \& Wiesner, R. (2008). Taschenatlas Physiologie. München: Urban \& Fischer. Recuperado de: http://shop.elsevier.de/medizinstudenten/taschenatlas-physiologiebuch/9783437419171/

Flouris, A. D. (January, 2011). Functional architecture of behavioural thermoregulation. European Journal of Applied Physiology, 111(1), 1-8. Recuperado de: http://link.springer.com/article/10.1007\%2Fs00421-010-1602-8 doi: 10.1007/s00421-010-1602-8

González-Alonso, J. (March, 2012). Human thermoregulation and the cardiovascular system. Experimental Physiology, 97(3), 340-346. Recuperado de: http://onlinelibrary.wiley.com/doi/10.1113/expphysiol.2011.058701/abstract doi: 10.1113/expphysiol.2011.058701

Harker, M. (April, 2013). Psychological sweating: a systematic review focused on aetiology and cutaneous response. Skin Pharmacology and Physiology, 26(2), 92-100. Recuperado de: http://www.karger.com/Article/FullText/346930 doi: $10.1159 / 000346930$

Harrold, J. A., Dovey, T. M., Blundell, J. E., \& Halford, J. C. (July, 2012). CNS regulation of appetite. Neuropharmacology, 63(1), 3-17. Recuperado de: http://www.sciencedirect.com/science/article/pii/S0028390812000196 doi: 10.1016/j.neuropharm.2012.01.007

Hofmann, T., Elbelt, U., \& Stengel, A. (April, 2014). Irisin as a muscle-derived hormone stimulating thermogenesis - A critical update. Peptides, 54C, 89-100. Recuperado de: http://www.sciencedirect.com/science/article/pii/S0196978114000199 doi: 10.1016/j.peptides.2014.01.016

Johnson, J. M., \& Kellogg, D. L. (2010). Local thermal control of the human cutaneous circulation. Journal of Applied Physiology, 109(4), 1229-1238. Recuperado de: http://jap.physiology.org/content/109/4/1229 doi: 10.1152/japplphysiol.00407.2010

Journigan, V. B., \& Zaveri, N. T. (March, 2013). TRPM8 ion channel ligands for new therapeutic applications and as probes to study menthol pharmacology. Life Sciences, 92(8-9), 425-437. Recuperado de: http://www.sciencedirect.com/science/article/pii/S0024320512006601 doi: 10.1016/j.Ifs.2012.10.032

Kellogg, D. L., Zhao, J. L., Wu, Y., \& Johnson, J. M. (2012). Nitric oxide and receptors for VIP and PACAP in cutaneous active vasodilation during heat stress in humans. Journal of Applied Physiology, 113(10), 1512-1518. Recuperado de: http://jap.physiology.org/content/early/2012/09/04/japplphysiol.00859.2012 doi: 10.1152/japplphysiol.00859.2012

Konishi, M., Nagashima, K., Asano, K., \& Kanosue, K. (2003). Attenuation of metabolic heat production and cold-escape/warm-seeking behaviour during a cold exposure 
following systemic salt loading in rats. The Journal of Physiology, 551(Pt 2), 713720. Recuperado de: http://jp.physoc.org/content/551/2/713.full

doi: 10.1113/jphysiol.2003.040592

Konishi, M., Nagashima, K., \& Kanosue, K. (2002). Systemic salt loading decreases body temperature and increases heat-escape/cold-seeking behaviour via the central AT1 and V1 receptors in rats. The Journal of Physiology, 545(Pt 1), 289-296. Recuperado de: http://jp.physoc.org/content/545/1/289

doi: http://dx.doi.org/10.1113/jphysiol.2002.027029

Kummitha, C. M., Kalhan, S. C., Saidel, G. M., \& Lai, N. (September, 2014). Relating tissue/organ energy expenditure to metabolic fluxes in mouse and human: experimental data integrated with mathematical modeling. Physiological Reports, 2(9). Recuperado

http://onlinelibrary.wiley.com/doi/10.14814/phy2.12159/abstract

doi: $10.14814 /$ phy2.12159

Lin, C. H., Tokizawa, K., Nakamura, M., Uchida, Y., Mori, H., \& Nagashima, K. (2012). Hyperosmolality in the plasma modulates behavioral thermoregulation in mice: the quantitative and multilateral assessment using a new experimental system. Physiology and Behavior, 105(2), 536-543. Recuperado de: http://www.sciencedirect.com/science/article/pii/S0031938411004422 doi: 10.1016/j.physbeh.2011.09.006

Lumpkin, E. A., \& Caterina, M. J. (2007). Mechanisms of sensory transduction in the skin. Nature, 445(7130), 858-865. Recuperado de: http://www.nature.com/nature/journal/v445/n7130/full/nature05662.html doi: 10.1038/nature05662

Lynn, A. G., Gagnon, D., Binder, K., Boushel, R. C., \& Kenny, G. P. (2012). Divergent roles of plasma osmolality and the baroreflex on sweating and skin blood flow. American Journal of Physiology. Regulatory, Integrative and Comparative Physiology, 302(5), R634-642. Recuperado de: http://ajpregu.physiology.org/content/early/2011/12/09/ajpregu.00411.2011 doi: 10.1152/ajpregu.00411.2011

López-Dávila, A. (2014). Nota técnica: el uso de una camiseta adicional aumenta significativamente el grado de deshidratación durante la práctica del fútbol. Pensar en Movimiento, 2(12), 1-5. doi: http://dx.doi.org/10.15517/pensarmov.v12i2.15602

López, M., Alvarez, C. V., Nogueiras, R., \& Diéguez, C. (July, 2013). Energy balance regulation by thyroid hormones at central level. Trends in Molecular Medicine, 19(7), 418-427. Recuperado de: http://www.sciencedirect.com/science/article/pii/S1471491413000725 doi: 10.1016/j.molmed.2013.04.004 
Meriney, S. D., \& Dittrich, M. (2013). Organization and function of transmitter release sites at the neuromuscular junction. Journal of Physiology, 591(Pt 13), 3159-3165. Recuperado de: http://jp.physoc.org/content/591/13/3159.full?sid=a93bce39-e6ef4b0f-88e0-cf5f67048d63 doi: 10.1113/jphysiol.2012.248625

Morrison, S. F., Madden, C. J., \& Tupone, D. (2014). Central Neural Regulation of Brown Adipose Tissue Thermogenesis and Energy Expenditure. Cell Metabolism, 19(5), 741-756. http://www.sciencedirect.com/science/article/pii/S1550413114000631 doi: 10.1016/j.cmet.2014.02.007

Morrison, S. F., \& Nakamura, K. (2011). Central neural pathways for thermoregulation. Frontiers in Bioscience, 16, 74-104. doi: http://dx.doi.org/10.2741/3677

Morrison, S. F., Nakamura, K., \& Madden, C. J. (2008). Central control of thermogenesis in mammals. Experimental Physiology, 93(7), 773-797. Recuperado de: http://ep.physoc.org/content/93/7/773.abstract doi: 10.1113/expphysiol.2007.041848

Nagashima, K. (2006). Central mechanisms for thermoregulation in a hot environment. Industrial Health, 44(3), 359-367. doi: http://dx.doi.org/10.2486/indhealth.44.359

Nagashima, K., Nakai, S., Konishi, M., Su, L., \& Kanosue, K. (2001). Increased heatescape/cold-seeking behavior following hypertonic saline injection in rats. American Journal of Physiology. Regulatory, Integrative and Comparative Physiology, 280, R1031-1036. Recuperado de: http://ajpregu.physiology.org/content/ajpregu/280/4/R1031.full.pdf

Nakamura, K. (2011). Central circuitries for body temperature regulation and fever. American Journal of Physiology. Regulatory, Integrative and Comparative Physiology, 301(5), R1207-1228. Recuperado de: http://ajpregu.physiology.org/content/301/5/R1207 doi: 10.1152/ajpregu.00109.2011

Perino, A., Ghigo, A., Scott, J. D., \& Hirsch, E. (2012). Anchoring proteins as regulators of signaling pathways. Circulation Research, 111(4), 482-492. Recuperado de: http://circres.ahajournals.org/content/111/4/482.abstract?relatedurls=yes\&legid=circresaha;111/4/482 $\quad$ doi: 10.1161/CIRCRESAHA.111.262899

Purves, D., Augustine, J., Fitzpatrick, D., Hall, W., LaMantia, A., \& White, L. (2012). Neuroscience ( $5^{\text {ta }}$ ed.). Estados Unidos: Sinauer Associates, Inc. Recuperado de: http://www.sinauer.com/neuroscience-621.html

Rao, R. R., Long, J. Z., White, J. P., Svensson, K. J., Lou, J., Lokurkar, I., . . Spiegelman, B. M. (June, 2014). Meteorin-like Is a Hormone that Regulates Immune-Adipose 
Interactions to Increase Beige Fat Thermogenesis. Cell, 157(6), 1279-1291. doi: http://dx.doi.org/10.1016/j.cell.2014.03.065

Romanovsky, A. A., Almeida, M. C., Garami, A., Steiner, A. A., Norman, M. H., Morrison, S. F., . . Nucci, T. B. (2009). The transient receptor potential vanilloid-1 channel in thermoregulation: a thermosensor it is not. Pharmacological Reviews, 61(3), 228261. Recuperado de: http://pharmrev.aspetjournals.org/content/61/3/228.full doi: $10.1124 /$ pr.109.001263

Schepers, R. J., \& Ringkamp, M. (February, 2010). Thermoreceptors and thermosensitive afferents. Neuroscience and Biobehavioral Reviews, 34(2), 177-184. Recuperado de: http://www.sciencedirect.com/science/article/pii/S0149763409001559 doi: 10.1016/j.neubiorev.2009.10.003

Schlader, Z. J., Simmons, S. E., Stannard, S. R., \& Mündel, T. (2011). The independent roles of temperature and thermal perception in the control of human thermoregulatory behavior. Physiology and Behavior, 103(2), 217-224. Recuperado http://www.sciencedirect.com/science/article/pii/S0031938411000539 doi: 10.1016/j.physbeh.2011.02.002

Schlader, Z. J., Stannard, S. R., \& Mündel, T. (2010). Human thermoregulatory behavior during rest and exercise - a prospective review. Physiology and Behavior, 99(3), 269-275. Recuperado de: http://www.sciencedirect.com/science/article/pii/S0031938409003898 doi: 10.1016/j.physbeh.2009.12.003

Shibasaki, M., \& Crandall, C. G. (January, 2010). Mechanisms and controllers of eccrine sweating in humans. Frontiers in Bioscience, 2, 685-696. doi: http://dx.doi.org/10.2741/s94

Shibasaki, M., Wilson, T. E., \& Crandall, C. G. (2006). Neural control and mechanisms of eccrine sweating during heat stress and exercise. Journal of Applied Physiology, 100, 1692-1701. Recuperado de: http://jap.physiology.org/content/jap/100/5/1692.full.pdf doi: 10.1152/japplphysiol.01124.2005

Simmons, G. H., Wong, B. J., Holowatz, L. A., \& Kenney, W. L. (2011). Changes in the control of skin blood flow with exercise training: where do cutaneous vascular adaptations fit in? Experimental Physiology, 96(9), 822-828. Recuperado de: http://ep.physoc.org/content/96/9/822.full doi: 10.1113/expphysiol.2010.056176

Tanaka, M., Ootsuka, Y., McKinley, M. J., \& McAllen, R. M. (2007). Independent vasomotor control of rat tail and proximal hairy skin. The Journal of Physiology, 582(Pt 1), 421-433. Recuperado de: http://jp.physoc.org/content/582/1/421. full doi: 10.1113/jphysiol.2007.131292 
Terrien, J., Perret, M., \& Aujard, F. (2011). Behavioral thermoregulation in mammals: a review. Frontiers in Bioscience, 16, 1428-1444. doi: http://dx.doi.org/10.2741/3797

Tokizawa, K., Yasuhara, S., Nakamura, M., Uchida, Y., Crawshaw, L. I., \& Nagashima, K. (June, 2010). Mild hypohydration induced by exercise in the heat attenuates autonomic thermoregulatory responses to the heat, but not thermal pleasantness in humans. Physiology and Behavior, 100(4), 340-345. Recuperado de: http://www.sciencedirect.com/science/article/pii/S0031938410001149 doi: 10.1016/j.physbeh.2010.03.008

Tupone, D., Madden, C. J., \& Morrison, S. F. (2014). Autonomic regulation of brown adipose tissue thermogenesis in health and disease: potential clinical applications for altering BAT thermogenesis. Frontiers in Neuroscience, 8, 14. Recuperado de: http://journal.frontiersin.org/Journal/10.3389/fnins.2014.00014/abstract doi: 10.3389/fnins.2014.00014

Vinik, A. I., Nevoret, M., Casellini, C., \& Parson, H. (2013). Neurovascular function and sudorimetry in health and disease. Current Diabetes Reports, 13(4), 517-532. Recuperado de: http://link.springer.com/article/10.1007\%2Fs11892-013-0392-x doi: 10.1007/s11892-013-0392-x

Witjas-Paalberends, E. R., Güçlü, A., Germans, T., Knaapen, P., Harms, H. J., Vermeer, A. M., . . van der Velden, J. (2014). Gene-specific increase in the energetic cost of contraction in hypertrophic cardiomyopathy caused by thick filament mutations. Cardiovascular Research, 103(2), 248-257. doi: http://dx.doi.org/10.1093/cvr/cvu127

Wu, J., Cohen, P., \& Spiegelman, B. M. (2013). Adaptive thermogenesis in adipocytes: is beige the new brown? Genes and Development, 27, 234-250. Recuperado de: http://genesdev.cshlp.org/content/27/3/234?cited-

by=yes\&legid=genesdev;27/3/234 doi: $10.1101 / \mathrm{gad} .211649 .112$

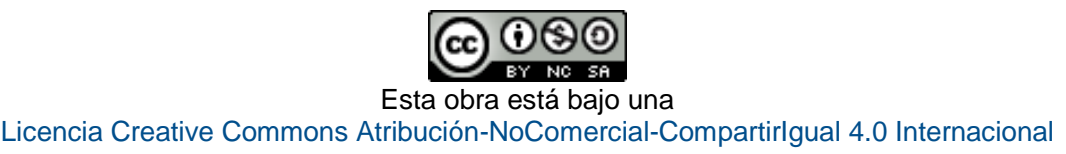


Tabla 2.

Anexos

Resumen esquematizado de la termorregulación refleja: respuesta termorreguladora al frío

\begin{tabular}{ll}
\hline Partes del arco reflejo & Descripción resumida \\
\hline Variable regulada & Temperatura del núcleo corporal.
\end{tabular}

Estímulo

a) Descenso de la temperatura de la piel o b) descenso de la temperatura del núcleo corporal. Solo esto último implica que la variable principal se desvía de su punto de ajuste.

Receptores

Neuronas termorreceptoras de frío que inervan la piel y tienen su soma en el ganglio de la raíz dorsal (DRG). Constituyen neuronas aferentes primarias.

Vías aferentes

Las neuronas termorreceptoras de frío estimulan y activan a neuronas "frías" $(C)$ de la lámina I del asta dorsal de la médula espinal (SCI). Estas últimas constituyen neuronas aferentes secundarias que estimulan y activan a neuronas del núcleo parabraquial lateral del mesencéfalo (LPB), específicamente en sus subnúcleos externos lateral (LPBel) y central (LPBC), que contienen neuronas aferentes terciarias (EI LPBc no se representa por falta de espacio).

Centro integrador Las células del LPBel estimulan y activan neuronas de la región preóptica hipotalámica (POA), específicamente en el subnúcleo preóptico mediano (MnPO). Estas neuronas secretan GABA al ser activadas, lo que inhibe a las neuronas "calientes" (H) del área preóptica medial (MPO) de la POA.

Debido a su inhibición, las neuronas calientes del MPO dejan de secretar GABA (neurotransmisor de naturaleza inhibitoria). Esto permite la activación de neuronas del núcleo dorsomedial del hipotálamo $(\mathrm{DMH})$ y del núcleo pálido raphe rostral de la médula oblongada (rRPA). El DMH causa a su vez la activación de una región de la médula oblongada ventromedial, rostral al polo rostral del complejo olivario inferior (rMR).

La disminución de la temperatura del núcleo corporal (estímulo b) también causa la inhibición de las neuronas "calientes" del MPO, tal y como ocurre por medio de las vías aferentes, ante disminución de la temperatura de la piel (estímulo a).

Vías eferentes

La activación del rMR y el rRPA activará neuronas preganglionares simpáticas de la columna intermedio lateral (IML) de la médula espinal. El rMR activará adicionalmente a motoneuronas alfa y gama, ubicadas en el asta ventral $(\mathrm{VH})$ de la médula espinal.

Las neuronas preganglionares simpáticas activarán neuronas postganglionares simpáticas. Esta sinapsis ocurre en la cadena paravertebral de ganglios simpáticos (SG), que recorre la médula espinal.

Órganos efectores Las neuronas postganglionares simpáticas y las motoneuronas alfa y gama estimulan a los diferentes órganos efectores, cuya activación permite retener y generar calor. Vasos sanguíneos cutáneos: vasoconstricción

Tejido adiposo pardo: termogénesis

Músculo esquelético: tremor

Corazón: taquicardia

Respuesta

Aumento de la temperatura del núcleo corporal.

Si todo el mecanismo se activó por disminución de la temperatura del núcleo corporal, se dio regulación por retrocontrol negativo y la temperatura del núcleo corporal vuelve a su punto de ajuste. Si el mecanismo se activó por descenso de la temperatura de la piel únicamente, se produce retrocontrol anticipado y la temperatura del núcleo corporal aumenta antes de que las condiciones ambientales la disminuyan.

Fuente: elaboración propia a partir de la bibliografía citada a lo largo del texto. Nótese que el código de colores de las figuras 1 y $\underline{2}$ para las diferentes partes del arco reflejo está conservado. 


\section{Tabla 3.}

Resumen esquematizado de la termorregulación refleja: respuesta termorreguladora al calor

\begin{tabular}{|c|c|}
\hline Partes del arco reflejo & Descripción resumida \\
\hline Variable regulada & Temperatura del núcleo corporal \\
\hline Estímulo & $\begin{array}{l}\text { a) Aumento de la temperatura de la piel o b) aumento de la temperatura del núcleo } \\
\text { corporal. Solo esto último implica que la variable principal se desvía de su punto de } \\
\text { ajuste. }\end{array}$ \\
\hline Receptores & $\begin{array}{l}\text { Neuronas termorreceptoras de calor que inervan la piel y tienen su soma en el ganglio } \\
\text { de la raíz dorsal (DRG). Constituyen neuronas aferentes primarias. }\end{array}$ \\
\hline Vías aferentes & $\begin{array}{l}\text { Las neuronas termorreceptoras de calor estimulan y activan a neuronas "calientes" (H) } \\
\text { de la lámina I del asta dorsal de la médula espinal (SCI). Estas últimas constituyen } \\
\text { neuronas aferentes secundarias que estimulan y activan a neuronas del núcleo } \\
\text { parabraquial lateral del mesencéfalo (LPB), específicamente en su subnúcleo dorsal } \\
\text { (LPBd), que son neuronas aferentes terciarias. }\end{array}$ \\
\hline Centro integrador & $\begin{array}{l}\text { Las células del LPBd estimulan y activan neuronas de la región preóptica hipotalámica } \\
\text { (POA), específicamente en el subnúcleo preóptico mediano (MnPO). Estas neuronas } \\
\text { secretan glutamato al ser activadas, lo que activa a las neuronas "calientes" (H) del área } \\
\text { preóptica medial (MPO) de la POA. } \\
\text { Debido a su activación, las neuronas calientes del MPO secretan GABA } \\
\text { (neurotransmisor de naturaleza inhibitoria). Esto causa la inactivación de neuronas del } \\
\text { núcleo dorsomedial del hipotálamo (DMH) y del núcleo pálido raphe rostral de la médula } \\
\text { oblongada (rRPA). La inactivación de las neuronas del DMH causa a su vez la } \\
\text { inactivación de ciertas neuronas de una región de la médula oblongada ventromedial, } \\
\text { rostral al polo rostral del complejo olivario inferior (rMR). } \\
\text { El aumento de la temperatura del núcleo corporal (estímulo b) también causa la } \\
\text { activación de las neuronas calientes del MPO, tal y como ocurre por medio de las vías } \\
\text { aferentes, ante aumento de la temperatura de la piel (estímulo a). }\end{array}$ \\
\hline Vías eferentes & $\begin{array}{l}\text { La inactivación del rMR y el rRPA inactivará neuronas preganglionares simpáticas de la } \\
\text { columna intermedio lateral (IML) de la médula espinal. La inactivación del rMR } \\
\text { inactivará adicionalmente a motoneuronas alfa y gama, ubicadas en el asta ventral (VH) } \\
\text { de la médula espinal. } \\
\text { Las neuronas preganglionares simpáticas no activarán a las neuronas postganglionares } \\
\text { simpáticas. Esta sinapsis ocurre en la cadena de ganglios simpáticos (SG), que recorre } \\
\text { la médula espinal. }\end{array}$ \\
\hline Órganos efectores & $\begin{array}{l}\text { La inactivación de las neuronas postganglionares simpáticas y las motoneuronas alfa y } \\
\text { gama eliminará el estímulo a los diferentes órganos efectores y su inactivación permite } \\
\text { eliminar calor. } \\
\text { Vasos sanguíneos cutáneos: eliminación de vasoconstricción (vasodilatación pasiva) } \\
\text { Tejido adiposo pardo: eliminación de termogénesis } \\
\text { Músculo esquelético: eliminación de tremor } \\
\text { Corazón: taquicardia se presenta tanto por RTF como por RTC } \\
\text { Activación de neuronas postganglionares simpáticas colinérgicas produce: } \\
\text { Vasodilatación neurogénica activa de vasos sanguíneos } \\
\text { Sudoración por activación de las glándulas sudoríparas }\end{array}$ \\
\hline Respuesta & $\begin{array}{l}\text { Disminución de la temperatura del núcleo corporal. } \\
\text { Si todo el mecanismo se activó por aumento de la temperatura del núcleo corporal, se } \\
\text { dio regulación por retrocontrol negativo y la temperatura del núcleo corporal vuelve a su } \\
\text { punto de ajuste. Si el mecanismo se activó por aumento de la temperatura de la piel } \\
\text { únicamente, se produce retrocontrol anticipado y la temperatura del núcleo corporal } \\
\text { disminuye antes de que las condiciones ambientales la aumenten. }\end{array}$ \\
\hline
\end{tabular}

Fuente: elaboración propia a partir de la bibliografía citada a lo largo del texto. Nótese que el código de colores de las figuras $\underline{1}$ y $\underline{2}$ para las diferentes partes del arco reflejo está conservado. 